\title{
Article \\ Nanostructured Molybdenum Oxides from Aluminium-Based Intermetallic Compound: Synthesis and Application in Hydrogen Evolution Reaction
}

\author{
Deepti Raj ${ }^{1}\left(\mathbb{D}\right.$, Federico Scaglione ${ }^{1, *} \mathbb{C}$, Gianluca Fiore ${ }^{1}$, Federica Celegato ${ }^{2}$ and Paola Rizzi $^{1}(\mathbb{D}$ \\ 1 Dipartimento di Chimica and Centro Interdipartimentale NIS (Nanostructured Interfaces and Surfaces), \\ Università di Torino, V. Giuria 7, 10125 Turin, Italy; deepti.raj@unito.it (D.R.); gianluca.fiore@unito.it (G.F.); \\ paola.rizzi@unito.it (P.R.) \\ 2 Istituto Nazionale di Ricerca Metrologica (INRIM), Str. Delle Cacce 91, 10135 Turin, Italy; f.celegato@inrim.it \\ * Correspondence: federico.scaglione@unito.it
}

Citation: Raj, D.; Scaglione, F.; Fiore,

G.; Celegato, F.; Rizzi, P.

Nanostructured Molybdenum Oxides from Aluminium-Based Intermetallic Compound: Synthesis and

Application in Hydrogen Evolution Reaction. Nanomaterials 2021, 11, 1313 https://doi.org/10.3390/nano11051313

Academic Editor: Mikhael Bechelany

Received: 30 April 2021

Accepted: 13 May 2021

Published: 17 May 2021

Publisher's Note: MDPI stays neutral with regard to jurisdictional claims in published maps and institutional affiliations.

Copyright: (c) 2021 by the authors. Licensee MDPI, Basel, Switzerland. This article is an open access article distributed under the terms and conditions of the Creative Commons Attribution (CC BY) license (https:/ / creativecommons.org/licenses/by/ $4.0 /)$.

\begin{abstract}
Characterized by a large surface area to volume ratio, nanostructured metal oxides possess unique chemical and physical properties with applications in electronics, catalysis, sensors, etc. In this study, $\mathrm{Mo}_{3} \mathrm{Al}_{8}$, an intermetallic compound, has been used as a precursor to obtain nanostructured molybdenum oxides. It was prepared into ribbons by arc-melting and melt-spinning techniques. Single and double-step free corrosion of the as-quenched material have been studied in $1 \mathrm{M} \mathrm{KOH}, 1 \mathrm{M}$ $\mathrm{HF}$ and $1.25 \mathrm{M} \mathrm{FeCl}_{3}$ at room temperature. In both cases, nanostructured molybdenum oxides were obtained on a surface layer a few microns thick. Two of the as-prepared samples were tested for their electrocatalytic capability for hydrogen evolution reaction (HER) in $0.5 \mathrm{M} \mathrm{H}_{2} \mathrm{SO}_{4}$ giving low onset potential $(-50 \mathrm{mV},-45 \mathrm{mV})$, small Tafel slopes $\left(92 \mathrm{mV} \mathrm{dec}^{-1}, 9 \mathrm{mV} \mathrm{dec}^{-1}\right)$ and high exchange current densities $\left(0.08 \mathrm{~mA} \mathrm{~cm}^{-2}, 0.35 \mathrm{~mA} \mathrm{~cm}{ }^{-2}\right.$ respectively). The proposed nanostructured molybdenum oxides are cost-effective and sustainable due to the cheap and abundant starting material used and the simple synthetic route, paving the way for their possible application as HER electrocatalysts.
\end{abstract}

Keywords: nanostructured materials; molybdenum oxides; free corrosion; intermetallic compound; hydrogen evolution reaction

\section{Introduction}

Molybdenum is an attractive metal which is in widespread industrial usage owing to its excellent properties-high thermal and electrical conductivity, high melting point, low thermal expansion, low vapour pressure and high temperature and wear resistance [1-3]. As an alloying element it enhances the corrosion resistance and mechanical properties of steels [1,3]. Molybdenum compounds have an array of applications as well—gas sensors $[4,5]$, heterogeneous catalysis $[6,7]$, electrocatalysis $[4,8]$, capacitors $[4,9]$, electrochromism [10,11], photochromism [4,12], and lithium-ion batteries [13,14]. Chalcogenide derivatives of Mo have been evidently favorable as building blocks in nanomaterial design in photocatalysis and hydrogen evolution reaction (HER) $[15,16]$. Due to the variable oxidation states of molybdenum, tuning of the crystal structure, morphology and oxygen vacancy is facilitated, which makes its oxide compounds suitable for electrochemical activities. Synthesis and analytical detection of numerous vital molecules has been successfully achieved using molybdenum oxide-based heterogeneous catalysis [7,17]. As gas sensors, molybdenum oxides have been well applied to $\mathrm{NO}, \mathrm{NO}_{2}, \mathrm{CO}, \mathrm{H}_{2}, \mathrm{NH}_{3}$, and other gases $[1,5] . \mathrm{MoO}_{3}$ is a versatile compound with noteworthy applications in electronics, catalysis, sensors, energy-storage units, biosystems, superconductors, lubricants, thermoelectric and electrochromic systems, etc. [18,19].

As a clean, efficient and sustainable alternative to fossil fuels, hydrogen gas $\left(\mathrm{H}_{2}\right)$ has emerged to be of great importance for the future of energy generation and storage [20,21]. 
However, production of $\mathrm{H}_{2}$ from the electrocatalytic hydrogen evolution reaction (HER) still remains a challenge and has been intensively explored using a range of materials [22,23]. So far, noble metals, such as platinum, have shown the best performance as HER catalysts [20,24]. Nevertheless, the scarcity, substandard stability and high cost of these metals have been hugely limiting their usage $[25,26]$. Therefore, developing inexpensive earthabundant electrocatalysts for hydrogen evolution, with increased activity and stability, is very significant in the field of clean energy [20]. Due to the extensive variations and tunable properties, molybdenum-based materials have garnered rising interest in the electrocatalytic HER [27,28]. Molybdenum oxides [20,29] and other compounds such as $\mathrm{Mo}_{2} \mathrm{C}[30]$, $\mathrm{MoSe}_{2}$ [31], MoN [32] and $\mathrm{MoS}_{2}[33,34]$ have been the focus of active investigation as HER electrocatalysts with $\mathrm{MoS}_{2}$ being the most broadly studied which exhibited favourable catalytic activity.

Nanostructured metals and metal oxides possess enhanced surface area and augmented chemical and physical properties $[35,36]$. The main and easy route to obtain a nanostructured material starting from an alloy is the chemical or electrochemical etching conducted by means of aqueous media. In accordance with the alloy's initial composition and the applied condition, i.e., type, concentration, $\mathrm{pH}$ and temperature of the electrolyte, time of treatment, corrosion can be classified as general corrosion when the alloy is dissolved completely in the etching solution or selective when just one component of the alloy is maintained after the etching. The selective etching process can cause the dissolution of the less noble element and the oxidation of the other and, in some cases the formation of a nanostructured oxide of the remaining element; this is due to the etching condition in conjunction with the natural tendency of elements, such as molybdenum, chromium and aluminium [3], to easily passivate and react with the oxygen present in the environment. In particular, $\mathrm{Al}$ is dissolved during the selective corrosion of Mo-Al binary systems while Mo oxidizes and formation of a continuous passive layer occurs over the surface. This passive oxide film is superiorly stable in acidic $\mathrm{pH}$ and loses its stability as the $\mathrm{pH}$ of the solution rises due to the formation of soluble surface species $[1,37,38]$. In other words, due to the formation of a highly protective oxide film, acidic electrolytes are comparatively less corrosive to molybdenum while alkaline media allows for continuous dissolution of molybdenum oxides [1,39].

Herein we report the synthesis of nanostructured molybdenum oxides from a binary intermetallic compound, $\mathrm{Mo}_{3} \mathrm{Al}_{8}$, with the composition 28 at. $\% \mathrm{Mo}$ and 72 at. $\%$ Al. Selective single-step and double-step free corrosion have been performed in various electrolytes with different concentrations, namely $1 \mathrm{M} \mathrm{KOH}, 1 \mathrm{M} \mathrm{HF}$ and $1.25 \mathrm{M} \mathrm{FeCl}_{3}$ at room temperature playing with the time of the treatment. Taking advantage of their increased surface area and typically high number of active sites, the molybdenum oxide samples obtained have been tested as non-precious electrocatalysts for the HER. The materials reported in this paper have been obtained using comparatively cheap and abundant precursors and a simple, fast and sustainable synthetic route that do not involve the use of critical raw materials. They are characterised by a good overall HER activity, paving the way for possible application of these materials as HER electrocatalysts as cost-effective alternative to $\mathrm{Pt}$ and Pt-based electrocatalysts. Being free-standing and easy-to-handle materials, they can potentially be economical and sustainable candidates for large-scale industrial production.

\section{Materials and Methods}

$\mathrm{Mo}_{3} \mathrm{Al}_{8}$ master alloy of nominal composition 28 at. \% Mo and 72 at. \% $\mathrm{Al}$ was prepared by arc-melting bars of pure elements (99.999\% Mo and $99.999 \% \mathrm{Al}$ ) after evacuating and purging the furnace several times in Ti-gettered Ar atmosphere. The ingot was melt-spun from a boron nitride crucible (Edmund Bühler $\mathrm{GmbH}$, Bodelshausen, Germany) at a linear speed of $25 \mathrm{~m} \mathrm{~s}^{-1}$ onto a hardened $\mathrm{Cu}$ wheel in a closed chamber kept under a protective Ar atmosphere. 
Different trials of chemical and electrochemical corrosion were performed using electrolytes, namely $1 \mathrm{M} \mathrm{KOH}, 1 \mathrm{M} \mathrm{HF}$. $1.25 \mathrm{M} \mathrm{FeCl}_{3}, 1 \mathrm{M} \mathrm{H}_{2} \mathrm{SO}_{4}, 1 \mathrm{M} \mathrm{Na}_{2} \mathrm{~S}$ and piranha solution ( 3 parts $\mathrm{H}_{2} \mathrm{SO}_{4}$ : 1 part $\mathrm{H}_{2} \mathrm{O}_{2}$ ) for different durations at room temperature and $70{ }^{\circ} \mathrm{C}$. The samples reported in this paper were obtained from single and double-step free corrosion of the as-quenched alloy ribbon performed at room temperature for durations ranging from $1 \mathrm{~h}$ to $24 \mathrm{~h}$ in $1 \mathrm{M} \mathrm{KOH} \mathrm{(20} \mathrm{mL} \mathrm{solution} \mathrm{of} 1.122 \mathrm{~g} \mathrm{KOH}), 1 \mathrm{M} \mathrm{HF}(20 \mathrm{~mL}$ solution of $0.725 \mathrm{~mL} \mathrm{HF}$ from a $27.59 \mathrm{M}$ stock solution) and $1.25 \mathrm{M} \mathrm{FeCl}_{3}$ (20 mL solution of $3.244 \mathrm{~g} \mathrm{FeCl}_{3}$ ). All electrolytes were prepared from chemical grade reagents and deionized water. This synthesis was repeated several times in order to check the reproducibility and the same results were always obtained.

Samples were analyzed before and after treatments using a Panalytical X-pert X-ray Diffractometer in Bragg-Brentano geometry (Panalytical, Almelo, The Netherlands) with monochromatic $\mathrm{Cu} \mathrm{K} \alpha$ radiation, scanning electron microscopy (Inspect SEM, FEI) (FEI, Hillsboro, OR, USA), field-emission scanning electron microscopy (FIB-FESEM/EBSD/ EDS/TOF-SIMS Tescan S9000G microscope) (TESCAN, Brno, Czech Republic) and energydispersive X-ray spectroscopy (Oxford Ultim-Max 100 connected with the FESEM) (Oxford Instruments, Abingdon, UK).

The electrocatalytic activity of the obtained samples towards HER was evaluated in $0.5 \mathrm{M} \mathrm{H}_{2} \mathrm{SO}_{4}$ aqueous solution at room temperature, using a three-electrode cell (saturated $\mathrm{Ag} / \mathrm{AgCl}$ double-bridge reference electrode, Pt-grid counter and the sample as the working electrode). Linear sweep voltammetry (LSV) was performed at $2 \mathrm{mV} \mathrm{s}^{-1}$ for comparison with the data from the literature [40]. A sheet of pure $\mathrm{Pt}\left(2 \mathrm{~cm}^{2}\right)$ was polished on the surface as per conventional metallography and used for comparison with the samples in the same experimental conditions. All potentials were reported to the reversible hydrogen electrode (RHE) adding a value of $(0.199+0.059 \mathrm{pH}) \mathrm{V}$. The electrochemically active surface area of the samples (ECSA) was estimated using the double layer capacitance method [20,41,42]. All measurements were performed in $0.5 \mathrm{M} \mathrm{H}_{2} \mathrm{SO}_{4}$ solution using a three-electrode cell similar to that utilized for the HER tests. Cyclic Voltammetry (CV) CV curves were obtained in the potential range of $100 \mathrm{mV}$ around the open circuit potential (OCP), assuming that only non-Faradaic processes take place at the electrode-solution interface in this potential range, at scan rates of $10,20,30,40,50,70,90$ and $100 \mathrm{mV} / \mathrm{s}$. Then, at the middle of this potential range, the current obtained in the middle of each cycle (i.e., average of the cathodic current and the anodic current) was plotted against the scan rates mentioned above. The plots obtained are provided in the Supplementary Material (Figure S3). The current density was then normalized using the ECSA obtained for each sample.

\section{Results and Discussion}

Figure 1a shows the SEM secondary electron image of the as-quenched ribbon surface that exhibits a surface morphology with narrow sheet or plate-like structures woven together and overlapped closely. This morphology can be related to the shape of the crystalline grains as they grow on the surface during rapid solidification. Therefore, the presence of grain boundaries separating neighboring crystals is responsible for the roughness observed in Figure 1a. From this SEM image (Figure 1a) it is possible to estimate the crystals dimension that is on average below $10 \mu \mathrm{m}$. This particular morphology is of interest for the next steps of synthesis of the nanostructured molybdenum oxides being roughness and grain boundaries easy places for chemical etching.

Two phases were found to be present in the mirror-polished cross-section of the asprepared ribbon, i.e., $\mathrm{Mo}_{3} \mathrm{Al}_{8}$ and $\mathrm{AlMo}_{3}$, as observed in the back-scattered SEM images in Figure $1 \mathrm{~b}$, where the darker phase can be attributed to $\mathrm{Mo}_{3} \mathrm{Al}_{8}$ due to its lower average atomic number, while the lighter phase is related to $\mathrm{AlMo}_{3}$. The amount of $\mathrm{AlMo}_{3}$ in Figure $1 \mathrm{~b}$ is limited, meaning the composition of the master alloy ingot was just slightly above than what is required for obtaining only the linear compound $\mathrm{Mo}_{3} \mathrm{Al}_{8}$. The microstructure present in Figure $1 \mathrm{~b}$ can be clearly attributed to the formation of $\mathrm{Mo}_{3} \mathrm{Al}_{8}$ with 
a peritectic reaction at high temperature, followed by a eutectoid reaction at $1838 \mathrm{~K}$ being present areas in which alternated lamella of $\mathrm{Mo}_{3} \mathrm{Al}_{8}$ and $\mathrm{AlMo}_{3}$ are visible.
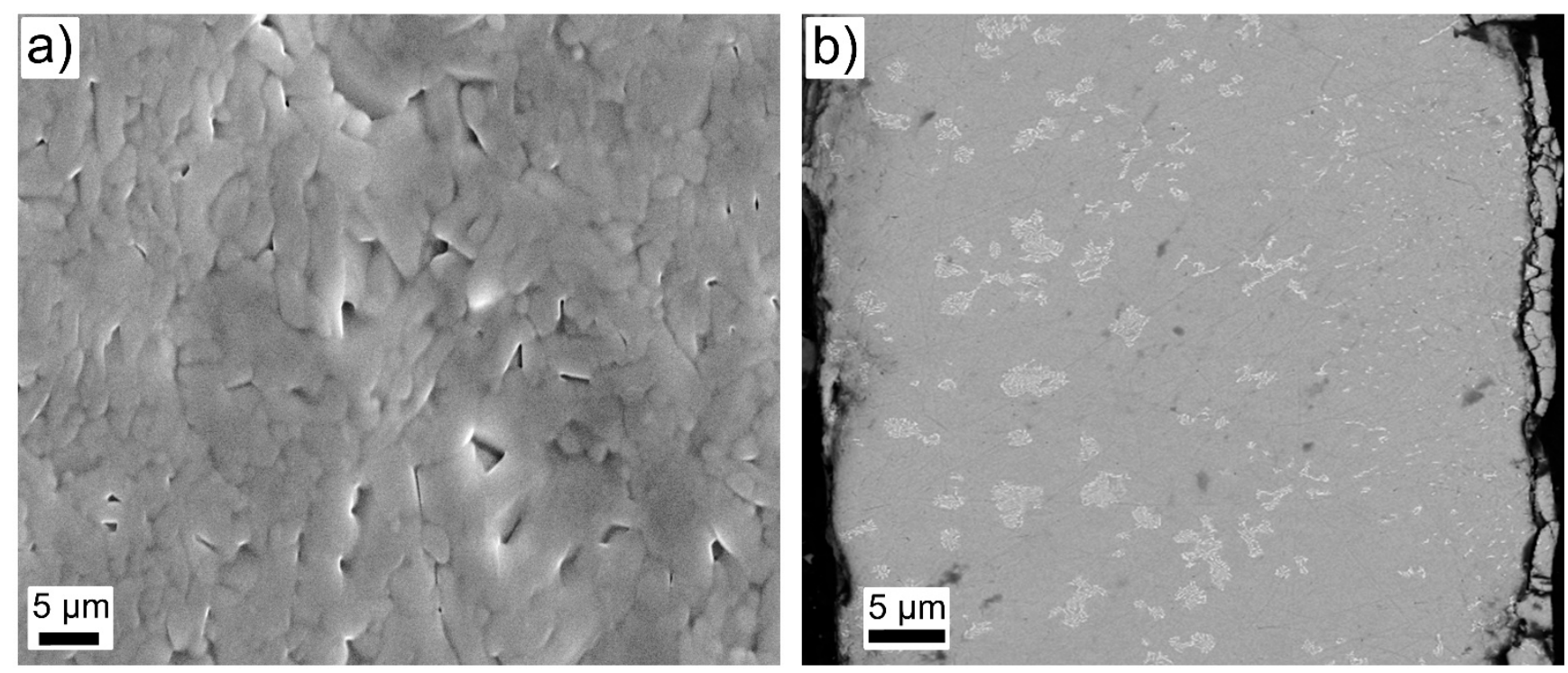

Figure 1. (a) Scanning electron microscopy-Secondary electron (SEM-SE) image of surface view of as-prepared ribbon and (b) SEM-back-scattered electron (BSE) image of mirror-polished cross-section of as-prepared ribbon.

The XRD data in Figure 2a show the typical patterns associated with $\mathrm{Mo}_{3} \mathrm{Al}_{8}$ intermetallic phase obtained from the wheel-side of the as-quenched ribbon. Phase determinations were made using Standard ICDD (International Centre for Diffraction Data) card no. 03-065-6867 for $\mathrm{Mo}_{3} \mathrm{Al}_{8}$ and 03-065-4685 for $\mathrm{AlMo}_{3}$. A textural effect at (-312) and (401) reflections are observed in the pattern taken from the air-side (Figure 2b): solidification front starts in the region of the ribbon which is in direct contact with the wheel of the meltspinning apparatus and then proceeds in the direction along which the heat is subtracted during the rapid quenching process, causing an orientation of crystals.

The composition of the as-spun ribbon was carefully analyzed by means of EDS, performing average spot analyses, compositional maps and line scans. The EDS spectrum (Figure $3 \mathrm{a}$ ) presents the main $\mathrm{Al}$ and Mo peaks; the average composition was determined to be 32 at. \% Mo and 68 at. \% Al with a standard deviation of 3 at. \%. The EDS compositional maps show a widespread and uniform presence of $\mathrm{Al}$ and Mo throughout the surface of the as-spun ribbon. Obviously, more Mo was found in the $\mathrm{AlMo}_{3}$ minority phase. The line scan data (Figure $3 b$ ) portrays a uniform trend in the Al and Mo intensity signals interrupted by a jump in the composition when the scanning line intercepts the $\mathrm{AlMo}_{3}$ phase. This observation further supports the findings from the SEM images and XRD analyses described above.

\subsection{Free Corrosion}

A number of trials of chemical and electrochemical corrosion were performed using an array of electrolytes for different durations at room temperature and $70{ }^{\circ} \mathrm{C}$, as mentioned above in the Materials and Methods section. Some of the obtained samples suffered from an excess of embrittlement and the SEM images can be found in Figure S1 of the Supplementary Material. These samples were not further studied being the goal of this study to propose mechanically stable, free-standing and easy-to-handle materials. In this respect, the most promising samples, in terms of mechanical stability and desired composition, turned out to be the ones prepared by single-step and double-step free corrosion using $\mathrm{KOH}, \mathrm{HF}$ and $\mathrm{FeCl}_{3}$ at room temperature varying the time of the treatment as demonstrated in Scheme 1. $\mathrm{KOH}$ and $\mathrm{HF}$ were selected as the etching electrolytes for selective corrosion of $\mathrm{Al}$. $\mathrm{FeCl}_{3}$ was used in the first step of the double-step free 
corrosion treatment to add another level of corrosion and facilitate nanostructuration in the morphology of the ribbon.

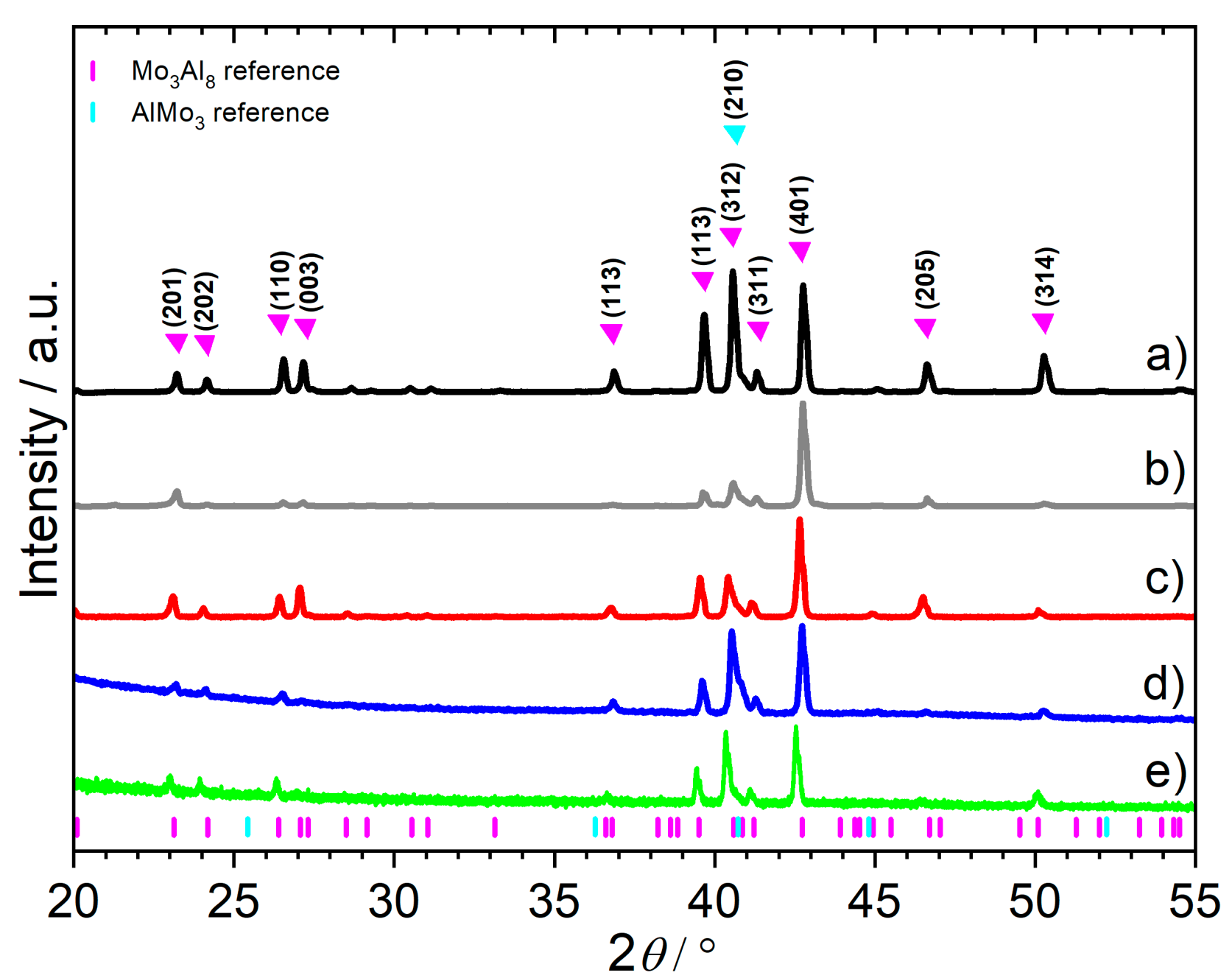

Figure 2. X-ray diffraction (XRD) pattern of (a) the wheel-side of the as-quenched ribbon; (b) the air-side of the as-quenched ribbon; (c) the air side of the sample obtained by single-step free corrosion in $1 \mathrm{M} \mathrm{KOH}$ at room temperature for $6 \mathrm{~h}$ (denoted as SS_KOH); (d) wheel side of the sample obtained by single-step free corrosion in $1 \mathrm{M} \mathrm{HF}$ at room temperature for $24 \mathrm{~h}$ (denoted as SS_HF) and; (e) wheel side of the sample obtained by double-step free corrosion first in $1.25 \mathrm{M} \mathrm{FeCl}_{3}$ for $1 \mathrm{~h}$ and then in $1 \mathrm{M} \mathrm{HF}$ for $6 \mathrm{~h}$ both at room temperature (denoted as DS_1h).

From here onwards the samples have been denoted in the following manner-the sample prepared by single-step free corrosion in $1 \mathrm{M} \mathrm{KOH}$ at room temperature for $6 \mathrm{~h}$ is SS_KOH; the sample prepared by single-step free corrosion in $1 \mathrm{M} \mathrm{HF}$ at room temperature for $24 \mathrm{~h}$ is SS_HF; the sample prepared by double-step free corrosion first in $1.25 \mathrm{M} \mathrm{FeCl}_{3}$ for $1 \mathrm{~h}$ and then in $1 \mathrm{M} \mathrm{HF}$ for $6 \mathrm{~h}$ both at room temperature is DS_1h and; the sample prepared by double-step free corrosion first in $1.25 \mathrm{M} \mathrm{FeCl}_{3}$ for $3 \mathrm{~h}$ and then in $1 \mathrm{M} \mathrm{HF}$ for $6 \mathrm{~h}$ both at room temperature is DS_3h.

\subsubsection{Single-Step Free Corrosion}

With the intent to remove the maximum amount of $\mathrm{Al}$ and induce the nanostructural roughening in the whole thick ness of the sample, free corrosion was performed in $1 \mathrm{M}$ $\mathrm{KOH}$ for $6 \mathrm{~h}$ at room temperature and the obtained sample was characterized. 

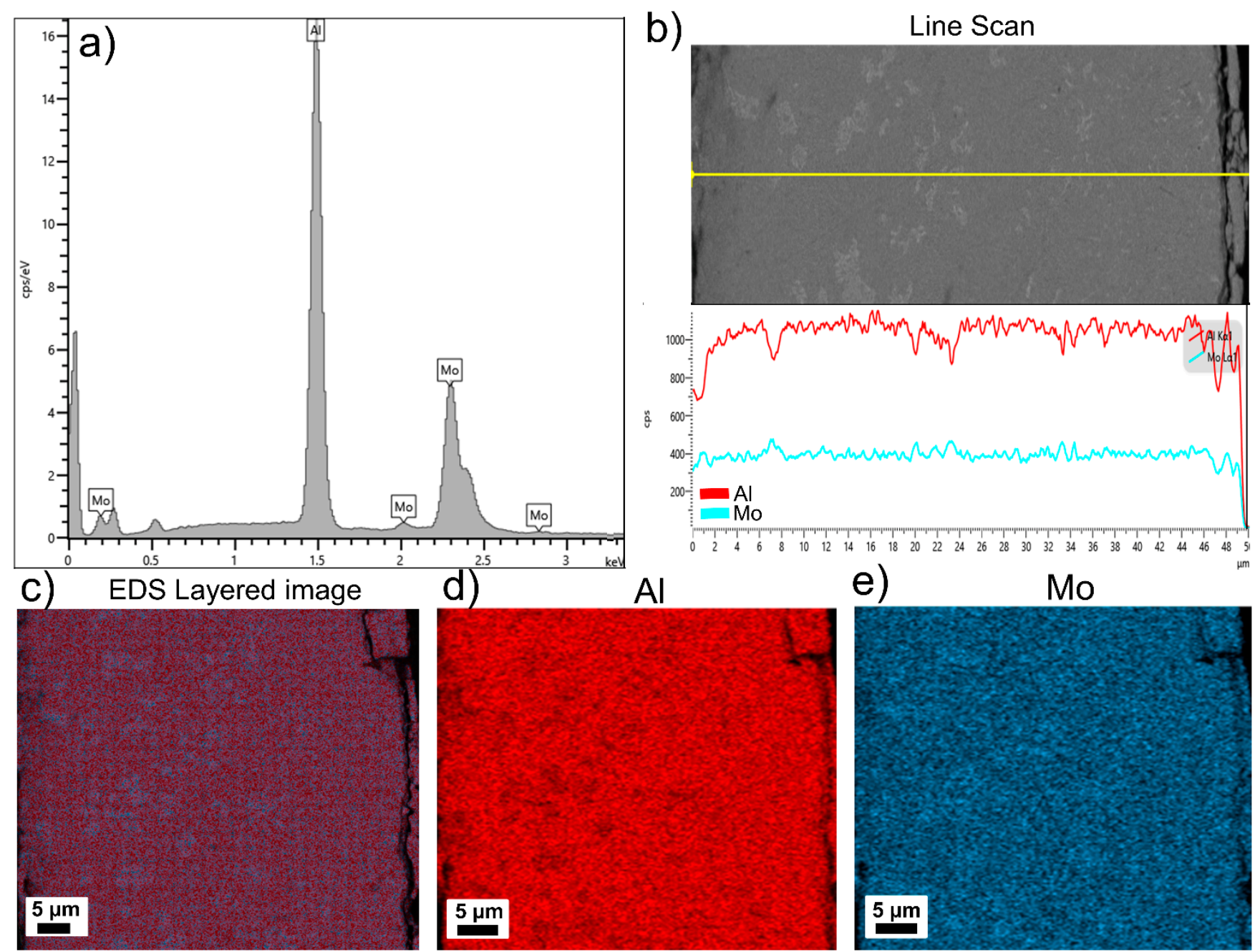

Mo

Figure 3. Energy-dispersive X-ray spectroscopy (EDS) analyses of the cross-section of the as-quenched ribbon: (a) EDS spectrum; (b) Line scan-red signal for $\mathrm{Al}$ and cyan signal for Mo; (c) Layered compositional map depicting $\mathrm{Mo}$ and $\mathrm{Al}$ content; (d) Map showing only Al content and; (e) Map showing only Mo content.

The XRD pattern of the air-side of SS_KOH (Figure 2c) resembles that of the air-side of the as-quenched ribbon (Figure $2 \mathrm{~b}$ ). The surface of the as-treated sample, SS_KOH (Figure 4a) is divided into crack patterns of micrometric size. Cracks could be due to stress corrosion and differences in volume between the pristine intermetallic alloy and the formed oxides. The inset of Figure 4 a reports a magnified image of the sample surface where a rough morphology can be observed, spread from the top of the patterned surface and extended only up to a few microns inside the cross-section. As for the rest of the crosssection, no nanostructured morphology was observed. From the compositional analysis by EDS, it is revealed that the ratio $\mathrm{Al} / \mathrm{Mo}$ on the surface and in the cross-section of the as-treated sample is similar to the ratio $\mathrm{Al} / \mathrm{Mo}$ of the as-quenched ribbon. As a result, no selective corrosion was achieved but a general corrosion with the formation of a scale composed by mixed $\mathrm{Al}$ and Mo oxides. By contrast, in XRD, just the pristine intermetallic alloy was observed. This could be explained by the low scattering factor of oxides with respect to metals and to the low symmetry of the $\mathrm{Mo}_{3} \mathrm{Al}_{8}$ phase. On one hand the oxides have a low scattering intensity with respect to metals, while on the other, weak peaks related to the oxide phases can be superimposed by the high number of peaks related to the $\mathrm{Mo}_{3} \mathrm{Al}_{8}$ phase. 


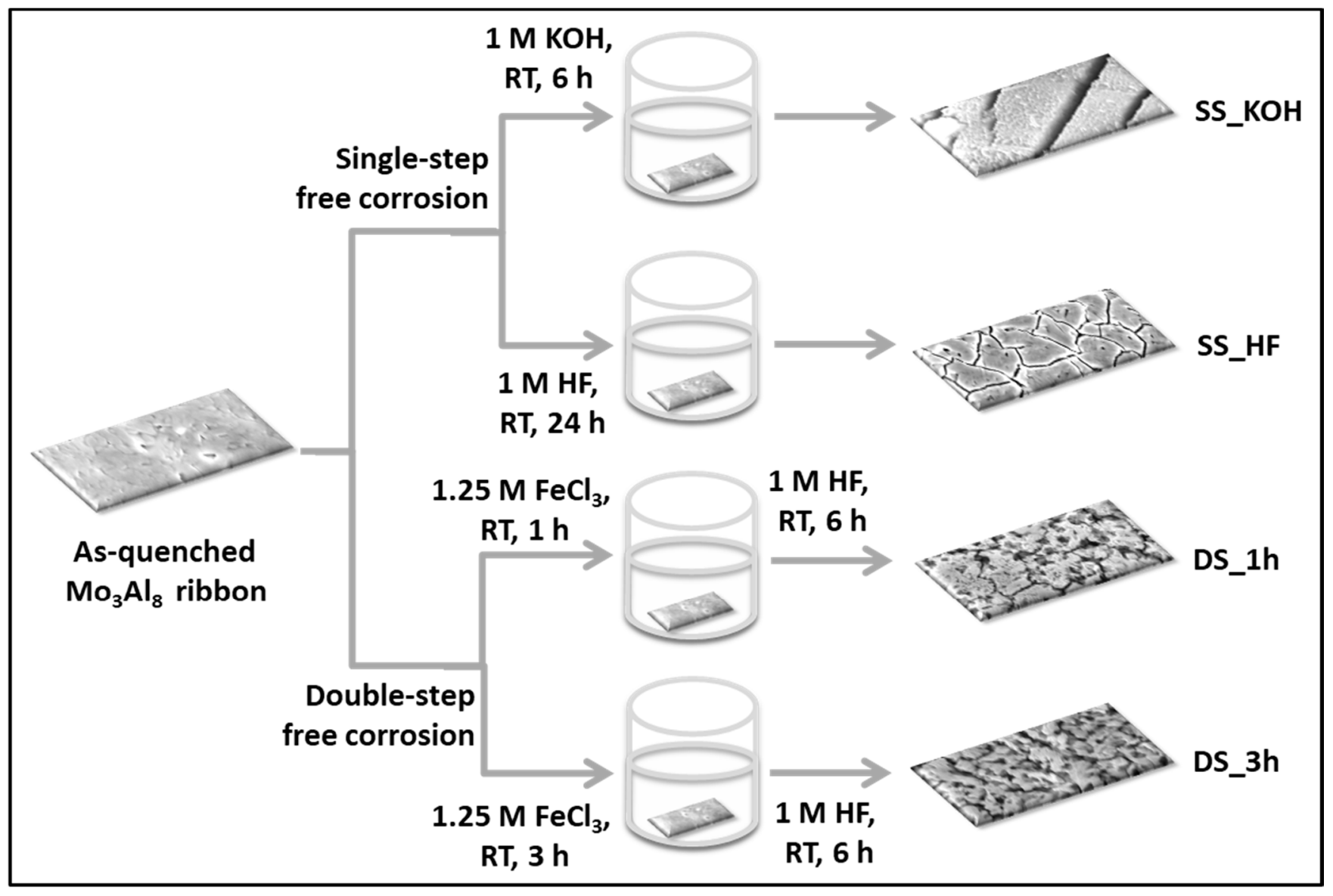

Scheme 1. Scheme demonstrating the overall free corrosion process.
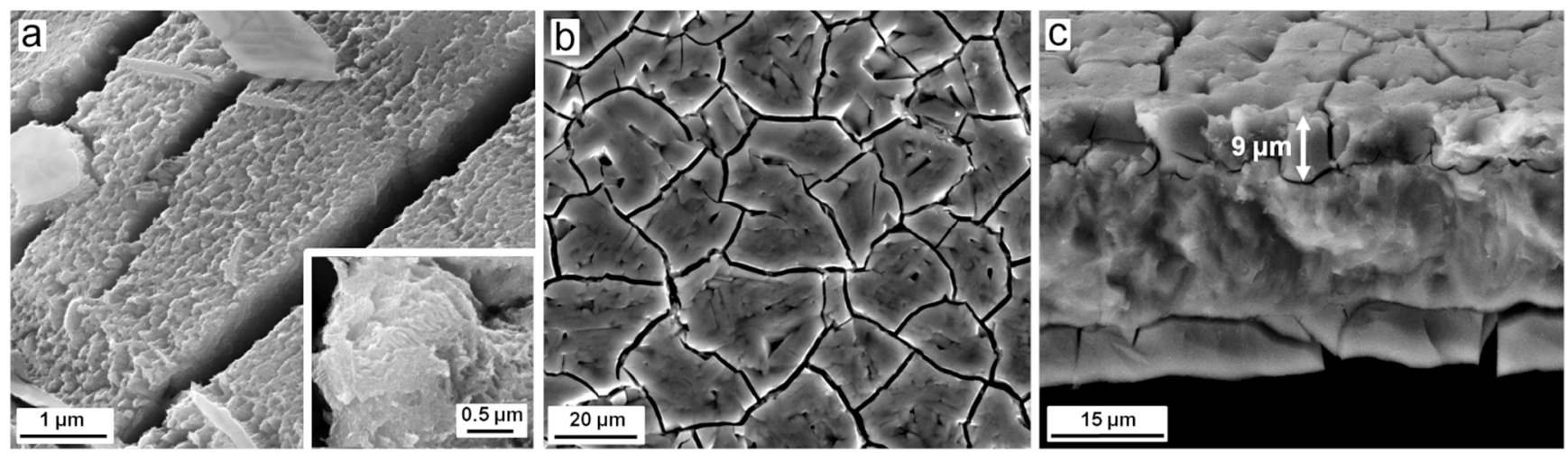

Figure 4. SEM images of (a) surface view of SS_KOH, (b) surface view of SS_HF and (c) cross-sectional view.

The effect of a different electrolyte was studied by using 1 M HF. High temperature treatment was avoided as it would be too harsh for the sample causing brittleness and worsening its stability. Accordingly, free corrosion was performed at room temperature in $1 \mathrm{M} \mathrm{HF}$ for $6 \mathrm{~h}$ but no appreciable formation of Mo oxides was obtained. When the treatment time was increased to $24 \mathrm{~h}$, the surface of the resultant sample (named SS_HF) was observed to be cracked, as already seen in the previous case, but inside the patterned region a compact layer of Mo oxides is present (Figure $4 \mathrm{~b}$ ). This cracked pattern is not extended in the whole cross-section of the ribbon but only up to about 9 microns approximately (Figure 4c). 
The XRD pattern shown in Figure $2 \mathrm{~d}$ presents a likeness to that of the wheel side of the as-quenched ribbon (Figure 2a) due to similar reason explained for the previous sample. In the EDS line scan in Figure 5 it can be seen that starting from the left part of the cross-sectional image the counts per second (cps) signals for Mo (in cyan) and Al (in blue) maintain their intensity as the scan continues along the thickness of the sample represented by the yellow line on the cross-sectional image. As soon as a void is encountered due to the inhomogeneity of the sample, there is a fall in both the signals. After crossing the void area, both the signals jump to their usual intensities. Towards the outer edge of the cross-section, highlighted by the red line segment $\mathrm{A}$, oxygen signal in green comes into the picture (within the red box A). Mo signal is slightly enhanced while Al signal is reduced drastically. This suggests the formation of the Mo oxide. In Figure 6a the compositional analysis of the cross-section of SS_HF done by EDS has been shown in the form of mappings. It can be seen that the selective corrosion has only taken place on the outer edge of the crosssection (highlighted by a mix of green and cyan colours) which represents the surface of the sample. A prominent attendance of oxygen is displayed in the corroded region along with the abundance of Mo. This implies that this corroded edge is composed of Mo oxide. Also, there are no notable traces of $\mathrm{Al}$ in this corroded layer. And, the bulk of the cross-section lacks any signs of corrosion as the $\mathrm{Al}$ and Mo compositions are not depleted and oxygen is absent. The EDS analysis shows the presence of $\mathrm{MoO}_{3}$ on the edges. Figure $6 \mathrm{~b}-\mathrm{d}$ display the elemental maps of $\mathrm{Mo}, \mathrm{O}$ and $\mathrm{Al}$ further clarifying the scenario in which $\mathrm{Mo}$ and $\mathrm{O}$ are prominently present on the outer edge while Al has disappeared.

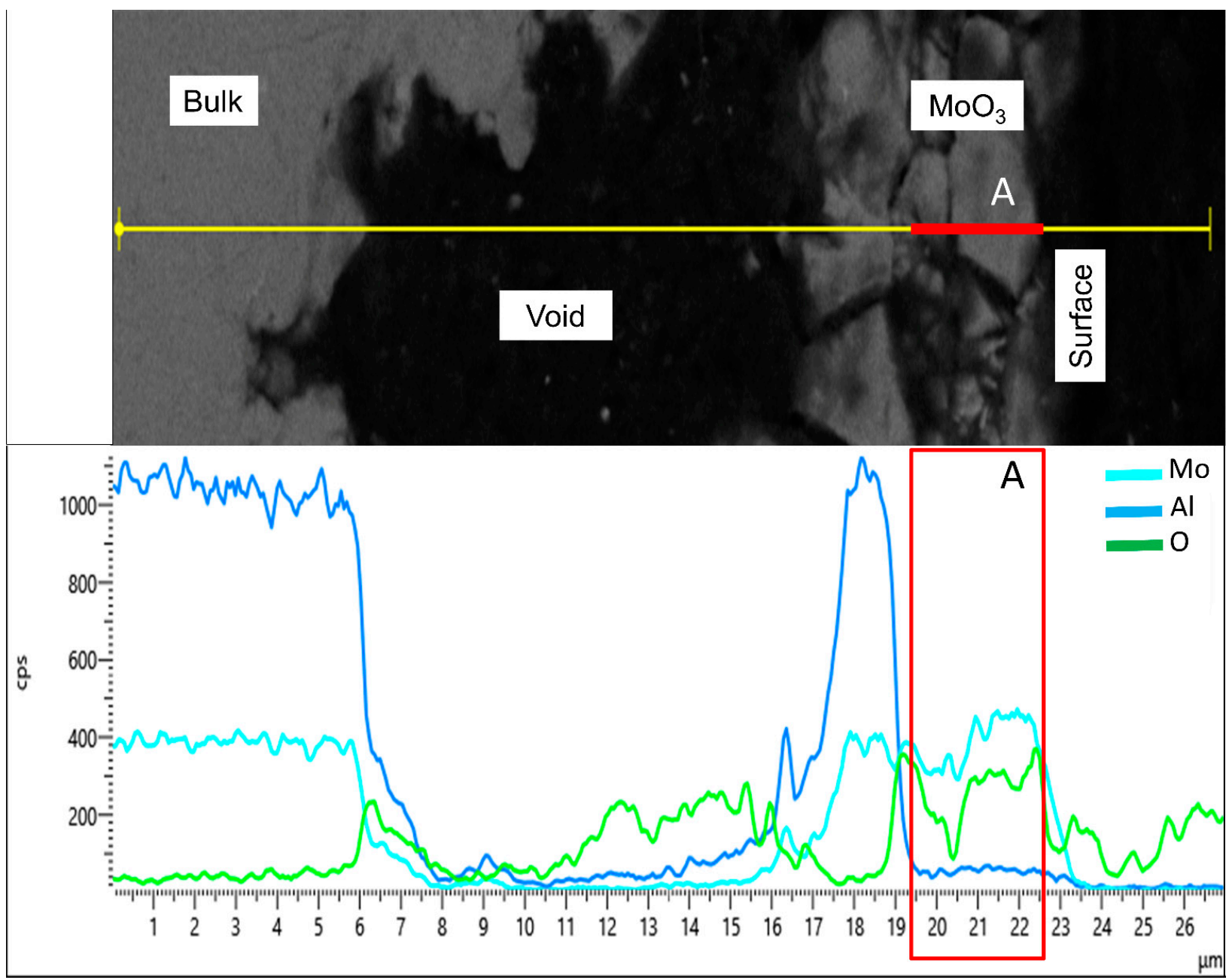

Figure 5. EDS line scan of SS_HF: blue signal for Al, cyan for Mo and green for O. 

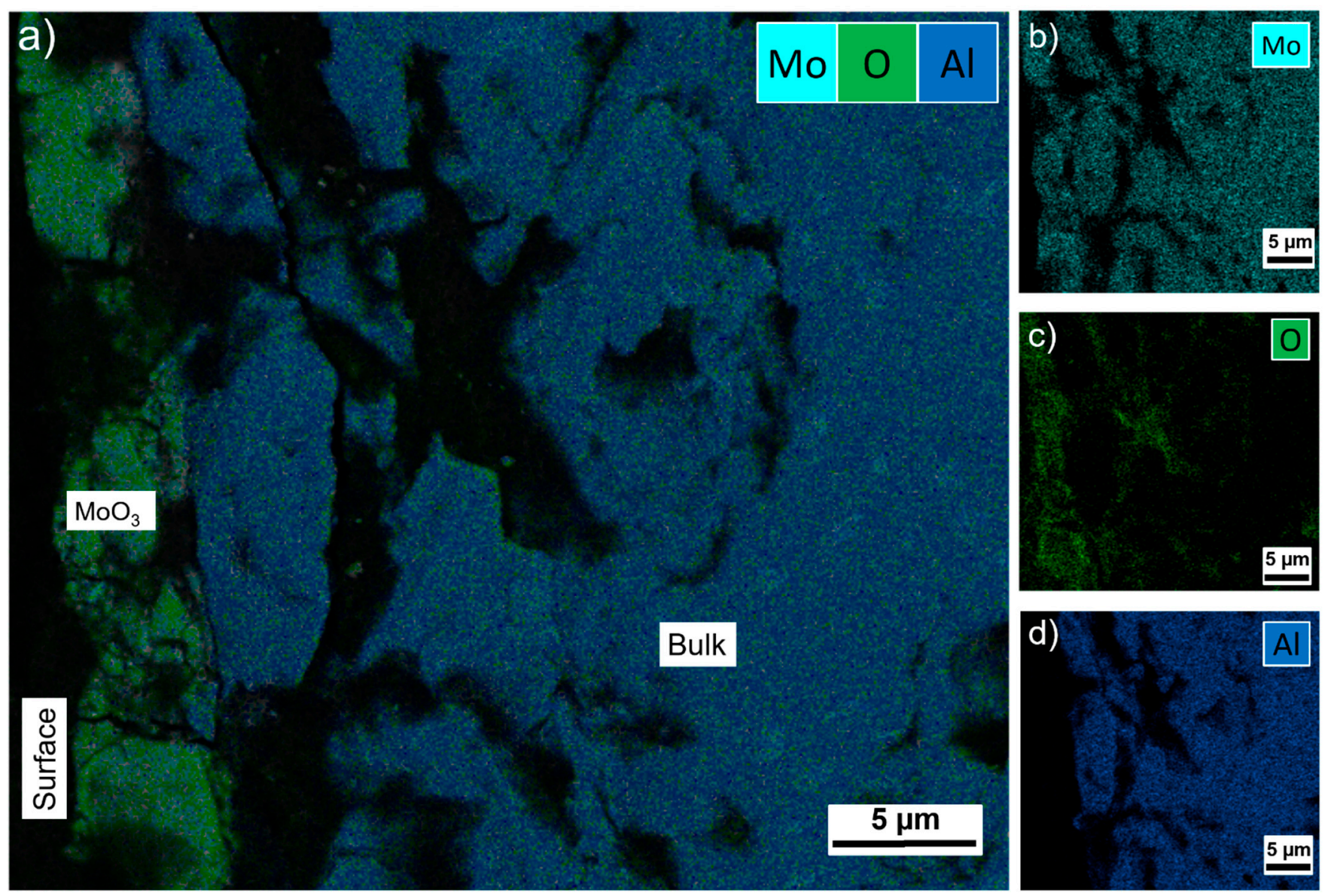

Figure 6. EDS analysis of SS_HF: (a) layered compositional map depicting Mo, O and Al content; (b) Mo elemental map; (c) O elemental map; and (d) Al elemental map.

The explanation for the behaviour observed in both the above samples, i.e., SS_KOH and SS_HF, can be attributed to the specific reactivity of $\mathrm{Al}$ and Mo in the experimental conditions applied for the selective corrosion treatment, i.e., $1 \mathrm{M} \mathrm{KOH}(\mathrm{pH}=14)$ and $1 \mathrm{M}$ $\mathrm{HF}(\mathrm{pH}=1.56)$ respectively. A superimposed Pourbaix diagram showing the regions of stability, passivation and corrosion of both elements has been reported in Figure 7a [1]. It depicts that Mo dissolves in aqueous solutions with neutral-to-alkaline $\mathrm{pH}$ due to the amplified stability of molybdenum oxyanions [3,43]. In a strongly basic condition and at a potential higher than $-0.89 \mathrm{~V}$ vs. SHE, Mo is unstable in the metallic state and is converted to molybdate $\left(\mathrm{MoO}_{4}{ }^{2-}\right)$ ion while for a wider range of potential $\mathrm{Al}$ is fully corroded. Figure $7 \mathrm{~b}$ shows the open-circuit potentials vs SHE of the pure $\mathrm{Al}$ and Mo, and the as-quenched $\mathrm{Mo}_{3} \mathrm{Al}_{8}$ ribbon while the open-circuit potentials vs RHE for the same can be found in Figure S2 in the Supplementary Material. In $1 \mathrm{M} \mathrm{KOH}$ (Figure 7b, solid lines) the open-circuit potentials are found to be $1.42 \mathrm{~V},-0.33 \mathrm{~V}$ and $-0.62 \mathrm{~V}$, respectively, for pure $\mathrm{Al}$ and $\mathrm{Mo}$, and as-quenched ribbon meaning that the pure elements and the ribbon are all in the condition of corrosion. Moreover, molybdenum is only weakly resistant to hydroxides [3] and oxidizing alkalis convert it into molybdate [44]. Hence, the morphology observed under alkaline etching in case of SS_KOH, in agreement with XRD and EDS results, is due to a general corrosion rather than a selective corrosion process. 


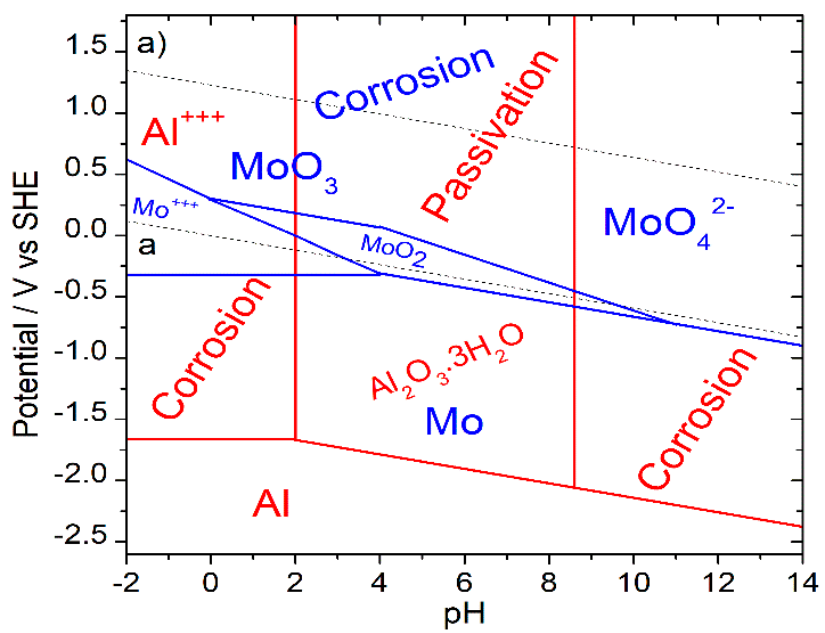

(a)

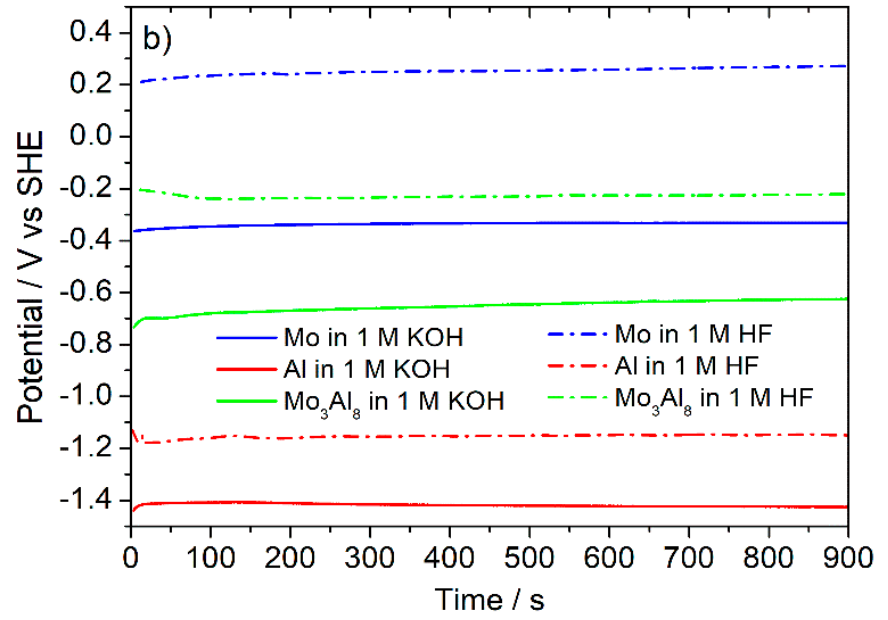

(b)

Figure 7. (a) Superimposed Pourbaix diagrams of pure Al and Mo showing the regions of stability, passivation and corrosion of each element. (b) Evolution of the open-circuit potential of pure $\mathrm{Al}$ and Mo, as references, and the as-quenched $\mathrm{Mo}_{3} \mathrm{Al}_{8}$ ribbon.

In the case of SS_HF, Figure $7 \mathrm{~b}$ represents the OCP curves obtained for pure Al and $\mathrm{Mo}$, and the as-quenched $\mathrm{Mo}_{3} \mathrm{Al}_{8}$ ribbon in $1 \mathrm{M} \mathrm{HF}$ in dot-dashed lines. The OCP value of $-1.15 \mathrm{~V}$ for pure $\mathrm{Al}$ lies in the corroded region of the Pourbaix diagram and that of $0.28 \mathrm{~V}$ for pure Mo lies in the oxidized region. The Pourbaix diagram shows that in aqueous solutions with acidic $\mathrm{pH}$, Mo forms passive oxides on its surface [3,43]. While Al is corroded in the strongly acidic condition $(\mathrm{pH} \leq 2)$, a value of $\mathrm{E}_{\mathrm{ocp}}=-0.22 \mathrm{~V}$ vs. SHE measured for the as-quenched ribbon falls in the region of $\mathrm{Mo}^{3+}$ ions. This means that being in acidic media, at first $\mathrm{Mo}^{3+}$ ions are formed at relatively low electrode potentials and then as the reaction proceeds the surface is covered with a passivating layer of $\mathrm{MoO}_{2}$ or $\mathrm{MoO}_{3}$ [44]. In addition, molybdenum does not dissolve appreciably in non-oxidizing acids [44] and is relatively unaffected by the presence of halide ions, relatively resistant to most localized corrosion processes [3]. Therefore, it has good performance in hydrohalide acids, i.e., HF in this case [3]. As a consequence, selective corrosion takes place where $\mathrm{Al}$ is dissolved on the top surface while Mo undergoes oxidation and forms a compact passive oxide layer $[37,43]$ on the terraces which results in the formation of nanostructured molybdenum oxides.

\subsubsection{Double-Step Free Corrosion}

The double-step free corrosion was undertaken with the intention that applying dedicated individual steps of general and selective corrosion would result in a Mo oxiderich product with improved nanostructural morphology and surface area. The first step of the treatment was particularly dedicated to corrode and expose the surface using a corrosive electrolyte. This would cause roughness and simultaneously remove stable Al and Mo oxides covering the sample surface that can impede the dissolution process. The second step was targeted to remove the $\mathrm{Al}$ content via selective corrosion with the help of a suitable electrolyte.

For the first step, $\mathrm{FeCl}_{3}$ was chosen which is a well-known corrosive agent and has been reported in literature as being successfully used as an etchant for Al and its alloys [45]. In addition, oxidizing conditions severely reduce molybdenum's corrosion resistance, and aeration causes a significant boost in corrosion [3]. Therefore, $\mathrm{FeCl}_{3}$, being a reducing acid containing oxidizer, rapidly attacks molybdenum.

The as-quenched ribbon was treated in $1.25 \mathrm{M} \mathrm{FeCl}_{3}$, chosen from literature [45], at room temperature from $1 \mathrm{~h}$ to $8 \mathrm{~h}$. Only the samples obtained after $1 \mathrm{~h}$ and $3 \mathrm{~h}$ of treatment were taken into account as the rest suffered from brittleness due to the prolonged 
treatments. However, the observed pitting corrosion was limited to the surface of the obtained samples.

Considering the effect of HF in eliminating high amounts of Al observed for sample SS_HF as previously described, $1 \mathrm{M} \mathrm{HF}$ was used for the second step and the free corrosion was performed for $6 \mathrm{~h}$ at room temperature for the samples treated for $1 \mathrm{~h}$ and $3 \mathrm{~h}$, namely DS_1h and DS_3h respectively. From the SEM images of DS_1h (Figure 8a,b) it can be observed that the sample acquired an inhomogeneous porosity as a result of pitting corrosion. After $6 \mathrm{~h}$ of treatment in HF, the sample was affected by the electrolyte on a surface layer of $3 \mu \mathrm{m}$. The composition was measured by the EDS which showed the presence of $\mathrm{MoO}_{3}$ on the surface. Figure 9 presents the line scan analysis of the crosssection in which the trends are similar to that already seen in the case of SS_HF. The cps signals for Mo (in cyan) and O (in green) are visible in the outer region of the cross-section (highlighted by the red line segment B and red box B) with negligible Al signal indicating the presence of Mo oxide. Continuing the scan, the oxide layer is passed by and the pristine phase appears which is demonstrated by the fall in $\mathrm{O}$ signal and simultaneous emergence of Al signal along with a slight decrease in Mo signal. The signals drop throughout the existence of the void which rise back once the void is crossed and the pristine phase prevails. The Mo signal in cyan retains its intensity throughout the cross-section demonstrating no significant decrease in the Mo concentration in the volume of the sample, suggesting that Mo is resistant to dissolution by HF and, rather, forms a passive oxide layer. It other words, the chemical etching using $1 \mathrm{M} \mathrm{HF}$ did not reduce the concentration of Mo but $\mathrm{Al}$ content has been notably removed by the etching treatment in a $3 \mu \mathrm{m}$ layer where Mo oxides have formed. Thus, HF has only acted upon $\mathrm{Al}$, as intended, selectively eliminating it and facilitating formation of Mo oxides. As analysed earlier in Section 3.1.1. 'Single-step free corrosion', the Pourbaix diagram (Figure 7a) validates this observation. Based on the OCP values of pure $\mathrm{Al}$ and Mo from Figure $7 \mathrm{~b}$, i.e., $-1.15 \mathrm{~V}$ and $0.28 \mathrm{~V}$ vs SHE respectively, pure $\mathrm{Al}$ lies in the corroded region of the diagram while pure Mo lies in the oxidized region. This means that treatment of the as-quenched ribbon $(\mathrm{OCP}=-0.22 \mathrm{~V}$ ) with $1 \mathrm{M}$ HF results in selective corrosion with $\mathrm{Al}$ being corroded while Mo undergoes oxidation forming a passivating layer of nanostructured Mo oxides. Figure 10a shows the Mo-oxide-rich outer-region of the cross-section highlighted by the mix of cyan and green signals for Mo and $\mathrm{O}$ respectively. Figure $10 \mathrm{~b}-\mathrm{d}$ display the elemental maps of Mo, $\mathrm{O}$ and $\mathrm{Al}$ that add up to the overall observation of the presence of Mo oxide on the sample surface. The bulk of the cross-section is protected from the corrosion as shown by the unchanged $\mathrm{Al}$ and Mo compositions, the Mo and Al signals in the line scan and the elemental maps.

In the case of DS_3h, the SEM images (Figure $8 \mathrm{c}, \mathrm{d}$ ) display a more homogeneous nanostructural surface with nanoplates. This can be linked to the extended duration of the first step of the corrosion process that increased the depth of etching and facilitated constant and stable treatment [45]. For the same reason a slightly nanostructural morphology can be noticed in the cross-section as well. The EDS results confirm the high content of Mo oxide on the surface by the action of HF in the second step. Observing this carefully, it can be inferred that the resultant microstructure resembles the as-quenched ribbon morphology. The corrosion must have started around the boundaries of the plate-like grains and the defects on the surface of the as-quenched ribbon (as shown in Figure 1 earlier). As a result, there is the formation of nanoplates along with grooves in the microstructure. The overlapping and compactness have been reduced compared to that in the as-quenched ribbon. The nanoplates also pose a roughened and layered texture increasing their surface area.

From the XRD data of DS_1h (Figure 2e) it is revealed that the obtained pattern largely mimics that of the as-quenched ribbon (Figure 2a). This is due to the negligible contribution of the $3 \mu \mathrm{m}$ layer of Mo oxide to the XRD pattern as it has been overlapped by the major contribution of the $\mathrm{Mo}_{3} \mathrm{Al}_{8}$ intermetallic phase present in the bulk and to the low scattering factor of oxides with respect to metals as previously described for the other samples. Similar results were obtained for DS_3h. 
Thus, a nanostructural molybdenum oxides rich sample with enhanced surface area was successfully obtained by using a double-step free corrosion process.
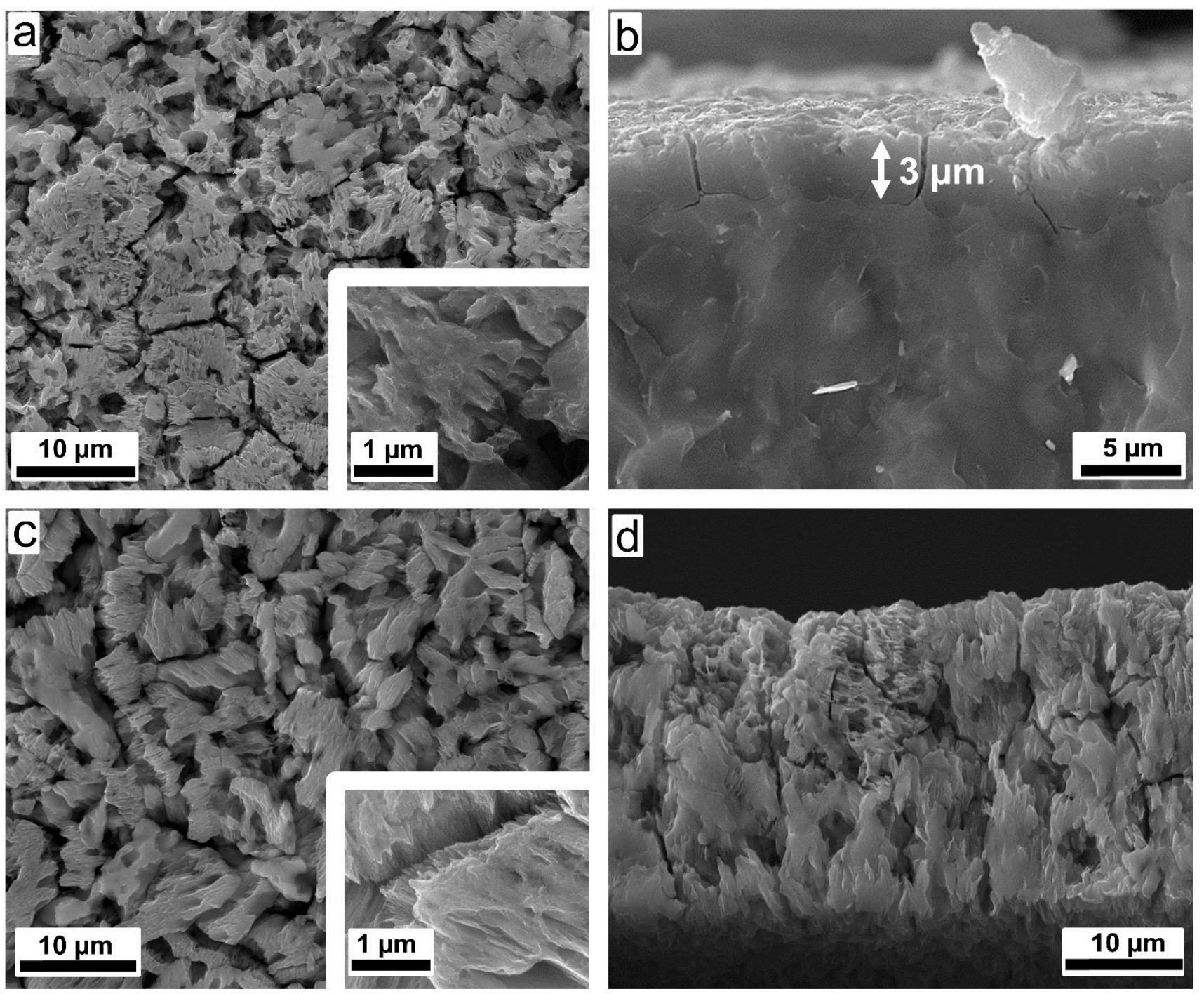

Figure 8. SEM images (on the left—surface view; on the right—cross-sectional view) of (a,b) DS_1h and (c,d) DS_3h.

\subsection{Hydrogen Evolution Reaction (HER)}

Since, Mo oxides have been proven as active electrocatalysts for HER $[20,27,29]$, we tested our samples, SS_HF and DS_1h, for the same.

Figure 11a reports LSV polarization curves for pure Pt, SS_HF and DS_1h. The current density involved in the whole range explored is always higher for Pt compared with that of SS_HF and DS_1h. The onset potential, which marks the onset of a large increment in current, comes out as $-50 \mathrm{mV}$ for SS_HF and $-45 \mathrm{mV}$ for DS_1h. These values top those of some already reported electrocatalysts such as $-80 \mathrm{mV}$ for core-shell nanocomposite based on Au nanoparticle@Zn-Fe-embedded porous carbons (Au@Zn-Fe-C) [46]; 198 mV for $\mathrm{CoTe}_{2}$ nanoparticles [47]; $-58 \mathrm{mV}$ for N-graphene/Co-embedded porous carbon derived from Metal Organic Frameworks [48]; and $82 \mathrm{mV}$ for hierarchical $\beta-\mathrm{Mo}_{2} \mathrm{C}$ nanotubes [49]. 


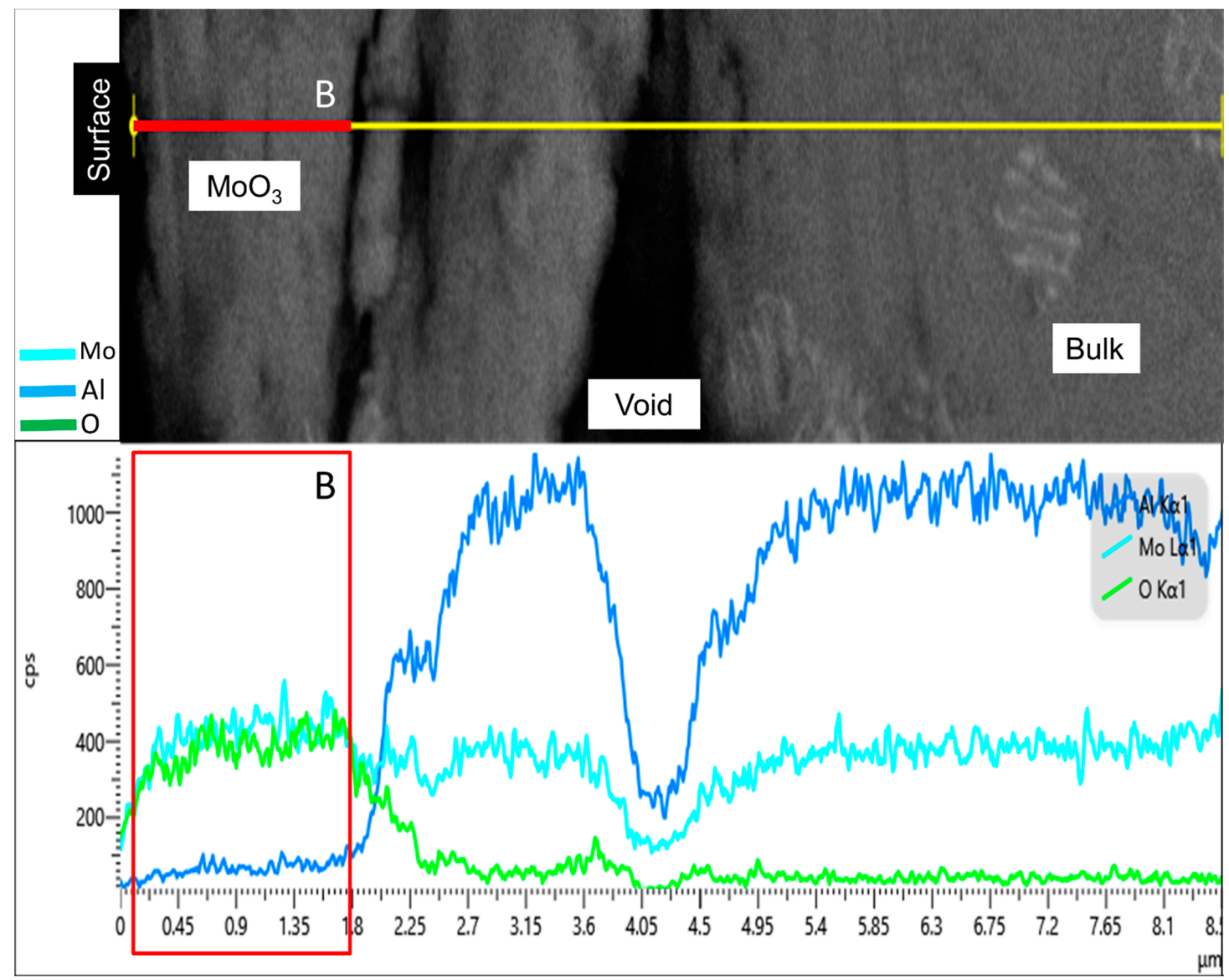

Figure 9. EDS line scan of DS_1h: cyan for Mo, blue signal for $\mathrm{Al}$ and green for $\mathrm{O}$.
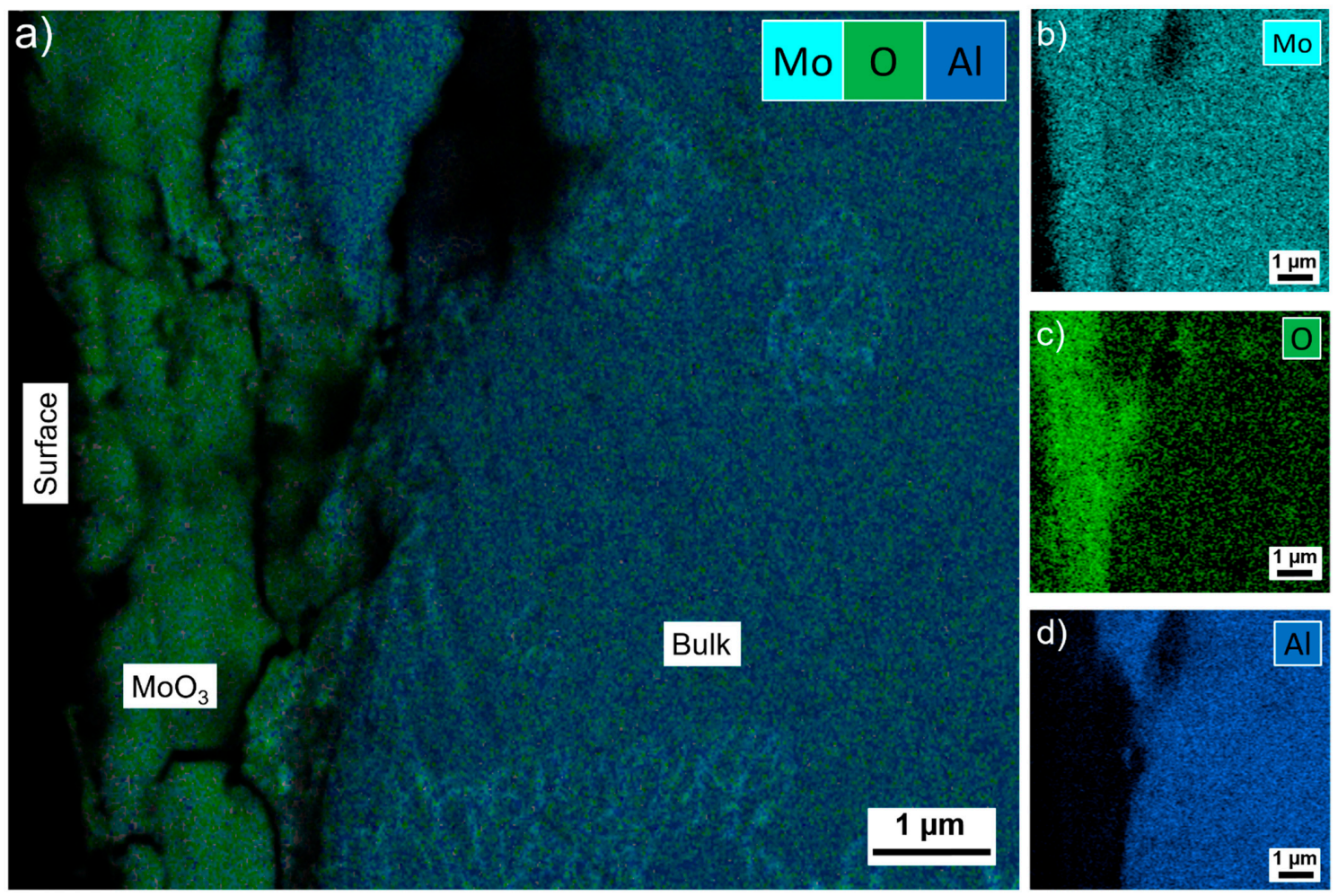

Figure 10. EDS analyses of DS_1h: (a) layered compositional map depicting Mo, $\mathrm{Al}$ and O content; (b) Mo elemental map; (c) O elemental map and; (d) Al elemental map. 

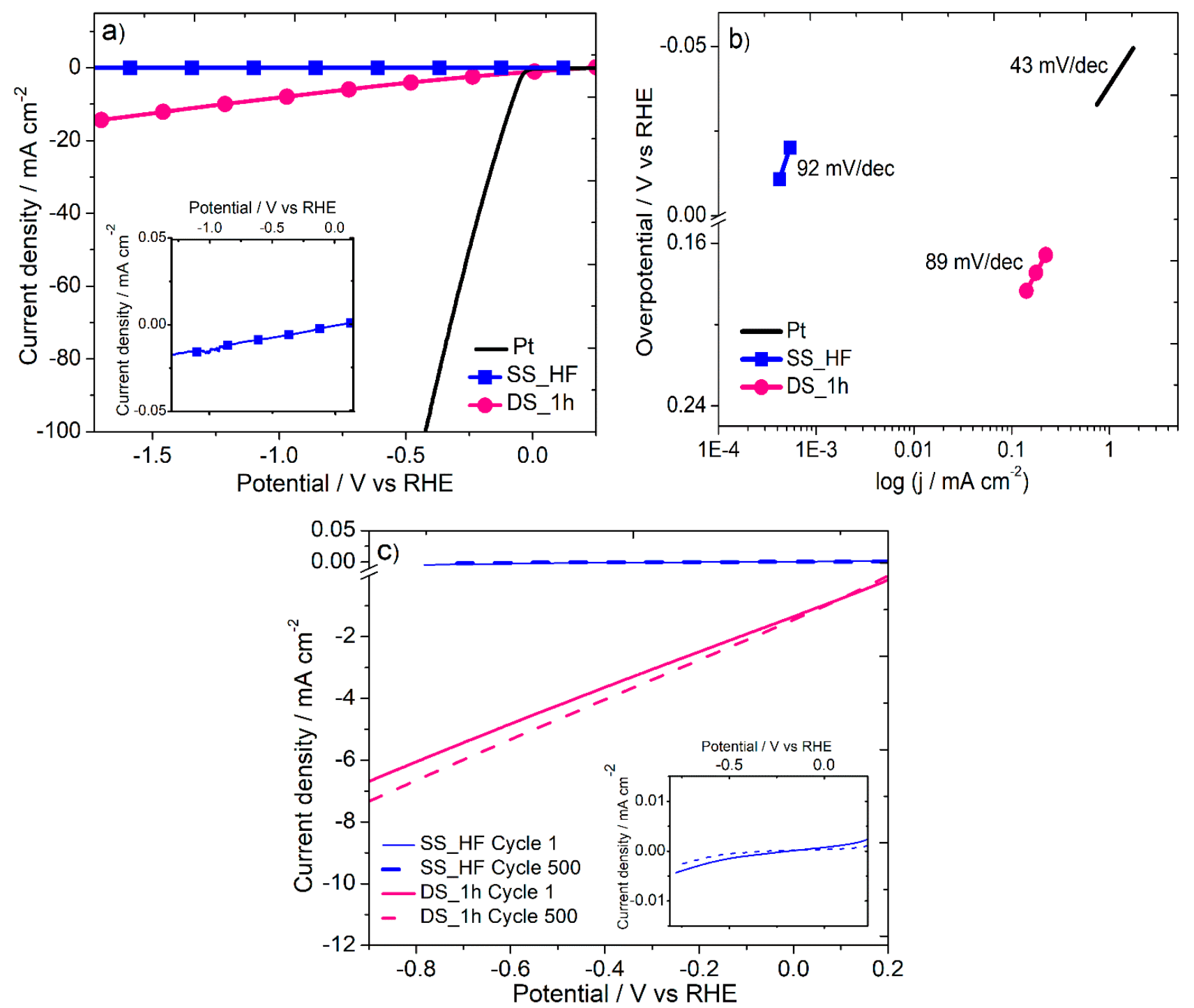

Figure 11. For pure Pt (solid black line), SS_HF (blue line with cubes) and DS_1h (dotted pink line) (a) linear sweep voltammetry (LSV) polarisation curves, inset shows the magnified view of the curve for SS_HF; (b) Tafel slope; and (c) LSV polarization curves after 500 cycles of potential scans for SS_HF and DS_1h, inset shows the magnified view of the curves for SS_HF.4.

DS_1h reaches the current density of $-10 \mathrm{~mA} \mathrm{~cm}{ }^{-2}$ at an overpotential of $-1.24 \mathrm{~V}$. The Tafel plots of the samples and the Pt reference were estimated in the region below the onset potential by linearly fitting data with the Tafel equation,

$$
\eta=b \log j+a
$$

where $\eta$ is the overpotential, $\mathrm{j}$ is the current density and $\mathrm{b}$ is the Tafel slope [50]. Tafel slope is a guide to determine the mechanism and the rate-determining step (r.d.s.) for the HER, based on the classical combination or Tafel reaction and (iii) desorption or Heyrovsky reaction [51,52]. The first step is ruled by the discharged process where a proton and a transferred electron interact, forming an adsorbed hydrogen atom on the electrode surface [53]. Then, the reaction could follow either the Tafel or the Heyrovsky reaction: in the former case, two adsorbed hydrogen atoms combine to evolve $\mathrm{H}_{2}$, whereas in the second case, an adsorbed hydrogen atom, a proton from the solution and another electron react to generate $\mathrm{H}_{2}$. The rate-determining step (r.d.s.) of the HER can be evaluated by the examination of the Tafel slope: a slope of $120 \mathrm{mV} / \mathrm{dec}$ or higher indicates that the r.d.s. 
is the Volmer reaction; slopes of $40 \mathrm{mV} / \mathrm{dec}$ are found when the r.d.s is the Heyrovsky reaction while when the r.d.s. is the Tafel step, slope decreases to a value of $30 \mathrm{mV} / \mathrm{dec}$ [54].

From Figure 11b, low Tafel slope values of $92 \mathrm{mV} / \mathrm{dec}$ for SS_HF and $89 \mathrm{mV} / \mathrm{dec}$ for DS_1h have been obtained signaling that Volmer is the rate-determining step [54,55]. This also suggests that with increasing applied potentials a faster surge in the HER rate will occur for both the samples. To compare with the literature, the Tafel slopes obtained in this work noticeably outdo the value of $130 \mathrm{mV} / \mathrm{dec}$ for $\mathrm{Au} @ \mathrm{Zn}-\mathrm{Fe}-\mathrm{C}$ mentioned previously [46]; $120 \mathrm{mV} / \mathrm{dec}$ for Co-doped $\mathrm{MoS}_{2}$ nanosheets, Co-MoS $2-0.5$ [56]; $370 \mathrm{mV} / \mathrm{dec}$ and $138 \mathrm{mV} / \mathrm{dec}$ for Pd-based nanoalloys assembled on reduced graphene oxide, rGO$\mathrm{Fe}_{48} \mathrm{Pd}_{52}$ and $\mathrm{rGO}-\mathrm{Au}_{48} \mathrm{Pd}_{52}$ respectively [57]; $125 \mathrm{mV} / \mathrm{dec}$ for Co-MOF, CTGU-5 [58]; $165 \mathrm{mV} /$ dec reported for Au-Pd alloy nanoparticles electrodeposited on microwave assisted sol-gel-derived carbon ceramic electrodes, namely Au-MWCCE [59]; $126 \mathrm{mV} / \mathrm{dec}$ for $\mathrm{N}$-graphene/co-embedded porous carbon derived from MOFs [48]; $94 \mathrm{mV} / \mathrm{dec}$ for nanostructured core-shell $\mathrm{CoS}_{2} @ \mathrm{MoS}_{2} / \mathrm{CP}$ [60]; mV/dec for $100 \mathrm{mV} / \mathrm{dec}$ for $\mathrm{Ni} / \mathrm{Mo}_{2} \mathrm{C}$ nanoparticles coated with graphene shells, $\mathrm{NiMo}_{2} \mathrm{C} @ \mathrm{C}$ [61]; $96 \mathrm{mV} / \mathrm{dec}$ for $\mathrm{Co}_{9} \mathrm{~S}_{8} / \mathrm{CoS}_{1.097} / \mathrm{rGO}$ prepared from Co-MOF [62]; and $116.9 \mathrm{mV} / \mathrm{dec}$ for Ni-doped $\mathrm{Mo}_{2} \mathrm{C}$ coating on carbon fiber paper, $\mathrm{Ni}-\mathrm{Mo}_{2} \mathrm{C} / \mathrm{CFP}[63]$.

From the intercept of the Tafel plot high values of exchange current densities for SS_HF and DS_1h are determined as $0.08 \mathrm{~mA} \mathrm{~cm}^{-2}$ and $0.35 \mathrm{~mA} \mathrm{~cm}^{-2}$, respectively. It is known that if the exchange current density is high, the surface of the electrode is more active which means that the charge has to overcome lower energy barrier in moving from electrolyte to the catalyst surface, and vice versa [64]. Accordingly, electrochemical reaction are is fast and high current generation takes place at a given overpotential [64]. The obtained exchange current density values surpass a number of those formerly reported in literature such as, $8.32 \times 10^{-9} \mathrm{~mA} \mathrm{~cm}^{-2}$ for the aforementioned Au-MWCCE [59]; $1.92 \times 10^{-3} \mathrm{~mA} \mathrm{~cm}^{-2}$ for $\mathrm{N}$-doped carbon coated $\mathrm{Co}-\mathrm{Ni}$ alloy with reduced graphene oxide decoration (CoNi@N-C/rGO) [65]; $0.017 \mathrm{~mA} \mathrm{~cm}^{-2}$ for hierarchical $\beta-\mathrm{Mo}_{2} \mathrm{C}$ nanotubes [49]; $9.2 \times 10^{-4} \mathrm{~mA} \mathrm{~cm}^{-2}$ for cocoon-like molybdenum sulfide nanostructures ( $\mathrm{MoS}_{2}$-Mo-1h) [66]; $5.9 \times 10^{-5} \mathrm{~mA} \mathrm{~cm}^{-2}$ for $\mathrm{CoTe}_{2}$ nanoparticles [47]; and $0.017 \mathrm{~mA} \mathrm{~cm}^{-2}$ reported for Pd-modified carbon fibre electrode [67,68]. The value of $0.35 \mathrm{~mA} \mathrm{~cm}^{-2}$ for DS_1h exceeds that of $0.13 \mathrm{~mA} \mathrm{~cm}{ }^{-2}$ for aforementioned $\mathrm{rGO}-\mathrm{Au}_{48} \mathrm{Pd}_{52}$ [57] and $0.126 \mathrm{~mA} \mathrm{~cm}^{-2}$ for nanostructured porous gold film [69]. Figure 11c illustrates the LSV polarization curves of SS_HF and DS_1h after 500 cycles of potential scans showing their efficient durability. Moreover, chronoamperometric measurements were also performed in $0.5 \mathrm{M} \mathrm{H}_{2} \mathrm{SO}_{4}$ applying a potential of $-0.48 \mathrm{~V}$ vs. RHE that remains constant during the measurement (Figure S4 in the Supplementary Material). The current is found to be generally stable for a period of more than $15 \mathrm{~h}$ for both the samples, once again confirming their remarkable stability for HER. The XRD patterns of the samples after the chronoamperometric stability test have been provided in Figure S5 in the Supplementary Material, showing no significant differences compared to the XRD patterns obtained before the test as already provided in Figure 2. SEM images were also obtained for the samples after the chronoamperometric stability test (Figure S6 in the Supplementary Material) where no changes in the morphology can be noticed. Moreover, EDS analysis was performed and no variations in the composition was detected with respect to the as prepared sample.

Active sites for molybdenum oxides are reported in literature to be related to variations in the oxidation states of the material. The possible anion vacancies, which are viewed as the electrochemical active sites, stimulate the HER [70,71], favour the electrochemical kinetics and can also significantly increase the electrical conductivity of the electrode [72]. A similar behaviour can be inferred for SS_HF and DS_1h samples.

Based on the above results it is clear that DS_1h shows smaller onset potential and Tafel slope than SS_HF. It also gives higher exchange current density than SS_HF. Moreover, only DS_1h is capable of reaching the current density of $-10 \mathrm{~mA} \mathrm{~cm}^{-2}$. These findings can be credited to its nanostructured morphology with larger surface area compared to that of SS_HF which increases the number of active sites enhancing the overall HER activity. 


\section{Conclusions}

Nanostructured molybdenum oxides have been obtained using an intermetallic $\mathrm{Mo}_{3} \mathrm{Al}_{8}$ precursor formed into ribbons by arc melting and melt-spinning techniques. The precursor was subjected to single and double-step free corrosion in $1 \mathrm{M} \mathrm{KOH}, 1 \mathrm{M} \mathrm{HF}$ and $1.25 \mathrm{M} \mathrm{FeCl}_{3}$ at room temperature for varying durations. In the case of single-step free corrosion using $\mathrm{KOH}$, the morphology, characterized by a rough surface with pores, was ascribed to general corrosion as confirmed by the EDS analysis which gave nominal composition on the sample surface and in the bulk. On treating the sample with HF, about $9 \mu \mathrm{m}$ thick layer of $\mathrm{MoO}_{3}$ was obtained. However, the layer was compact and the nanostructural morphology could not be achieved. Overall, HF was found to be much more active in removing the $\mathrm{Al}$ content from the sample surface and cross-section as compared to $\mathrm{KOH}$ in case of single-step free corrosion. When it came to double-step free corrosion, one of the samples, after treatment with $\mathrm{FeCl}_{3}$ for $1 \mathrm{~h}$ and $\mathrm{HF}$ for $6 \mathrm{~h}$, subsequently exhibited nanostructural morphology on the surface- $3 \mu \mathrm{m}$ thick layer rich in $\mathrm{MoO}_{3}$. None of the treatments could fully generate nanostructuration in the cross-section of the samples. However, in terms of both morphology and composition of the as-treated sample, double-step free corrosion proved to be better than the single-step. Two samples, i.e., SS_HF and DS_1h were selected to be tested as electrocatalysts for the HER in $0.5 \mathrm{M} \mathrm{H}_{2} \mathrm{SO}_{4}$. The measured values for SS_HF and DS_1h respectively are low onset potential of $-50 \mathrm{mV}$ and $-45 \mathrm{mV}$; small Tafel slopes $92 \mathrm{mV} \mathrm{dec}^{-1}$ and $89 \mathrm{mV} \mathrm{dec}^{-1}$ indicating Volmer as the rate-determining step; and high exchange current density of $0.08 \mathrm{~mA} \mathrm{~cm}^{-2}$ and $0.35 \mathrm{~mA} \mathrm{~cm}^{-2}$. DS_1h is able to reach a current density of $-10 \mathrm{~mA} \mathrm{~cm}^{-2}$ at an overpotential of $-1.24 \mathrm{~V}$. Both the samples show stability up to $15 \mathrm{~h}$ with no significant changes in their properties. As a whole, these are good findings considering the fact that the samples are obtainable via a fast, simple, low-cost and sustainable overall process including the starting material. The samples can be further developed to enhance their electrocatalytic activity in HER.

Supplementary Materials: The following are available online at https:/ / www.mdpi.com/article / 10.3390/nano11051313/s1, Figure S1: SEM images of samples obtained by different chemical and electrochemical corrosion trials; Figure S2: Evolution of the open-circuit potential vs RHE of pure Al, pure Mo and the as-quenched ribbon; Figure S3: Details of the ECSA analysis of SS_HF and DS_1h using the double layer capacitance method; Figure S4: HER stability tests for SS_HF and DS_1h by chronoamperometric method; Figure S5: XRD patterns of SS_HF and DS_1h after the chronoamperometric stability test; and Figure S6: SEM images of SS_HF and DS_1h after the chronoamperometric stability test in $0.5 \mathrm{M} \mathrm{H}_{2} \mathrm{SO}_{4}$ at $-0.48 \mathrm{~V}$ vs RHE for $15 \mathrm{~h}$.

Author Contributions: Conceptualization, P.R., F.C. and D.R.; methodology, D.R., F.S., G.F. and F.C.; validation, F.S. and P.R.; formal analysis, P.R.; investigation, D.R. and F.S.; resources, D.R. and F.S.; data curation, D.R. and F.S.; writing-original draft preparation, D.R.; writing-review and editing, D.R., F.S. and P.R.; supervision, F.S. and P.R. All authors have read and agreed to the published version of the manuscript.

Funding: This research was funded by Compagnia di San Paolo-Bando ex-post-Anno 2018.

Institutional Review Board Statement: Not applicable.

Informed Consent Statement: Not applicable.

Data Availability Statement: Data will be made available on request.

Acknowledgments: Acquisition of the SEM images has been performed thanks to NanoFacility Piemonte, INRIM.

Conflicts of Interest: The authors declare no conflict of interest.

\section{References}

1. Saji, V.S.; Lee, C.-W. Molybdenum, Molybdenum Oxides, and their Electrochemistry. ChemSusChem 2012, 5, 1146-1161. [CrossRef]

2. Stiefel, E.I. Molybdenum Compounds. In Kirk-Othmer Encyclopedia of Chemical Technology; Major Reference Works; John Wiley \& Sons, Inc.: Hoboken, NJ, USA, 2001; ISBN 9780471238966. 
3. Richardson, T.; Cottis, B.; Scantlebury, D.; Lindsay, R.; Lyon, S.; Graham, M. Shreir's Corrosion; Elsevier B.V.: Amsterdam, The Netherlands, 2010; ISBN 9780444527882.

4. Li, Y.X.; Yang, Q.B.; Yu, X.F.; Trinchi, A.; Sadek, A.Z.; Wlodarski, W.; Kalantar-zadeh, K. Nano structured molybdenum oxide gas sensors. In Proceedings of the SENSORS, 2006 IEEE, Daegu, Korea, 22-25 October 2006; pp. 232-234.

5. Imawan, C.; Steffes, H.; Solzbacher, F.; Obermeier, E. A new preparation method for sputtered $\mathrm{MoO}_{3}$ multilayers for the application in gas sensors. Sensors Actuators B Chem. 2001, 78, 119-125. [CrossRef]

6. Losse, S.; Junge, H. Recent Progress in Catalysis and Photochemistry for Energy Technologies. ChemSusChem 2010, 3, 1409-1410. [CrossRef]

7. Shi, X.R.; Wang, J.; Hermann, K. Theoretical cluster studies on the catalytic sulfidation of MoO 3 . J. Phys. Chem. C 2010, 114, 6791-6801. [CrossRef]

8. Kosminsky, L.; Matos, R.C.; Tabacniks, M.H.; Bertotti, M. Electrochemical codeposition of platinum and molybdenum oxides: Formation of composite films with distinct electrocatalytic activity for hydrogen peroxide detection. Electroanalysis 2003, 15, 733-738. [CrossRef]

9. Sugimoto, W.; Ohnuma, T.; Murakami, Y.; Takasu, Y. Molybdenum oxide/carbon composite electrodes as electrochemical supercapacitors. Electrochem. Solid-State Lett. 2001, 4, 145-147. [CrossRef]

10. Zheng, L.; Xu, Y.; Jin, D.; Xie, Y. Novel Metastable Hexagonal MoO3 Nanobelts: Synthesis, Photochromic, and Electrochromic Properties. Chem. Mater. 2009, 21, 5681-5690. [CrossRef]

11. Hsu, C.S.; Chan, C.C.; Huang, H.T.; Peng, C.H.; Hsu, W.C. Electrochromic properties of nanocrystalline $\mathrm{MoO}_{3}$ thin films. Thin Solid Film. 2008, 516, 4839-4844. [CrossRef]

12. He, T.; Yao, J. Photochromism of molybdenum oxide. J. Photochem. Photobiol. C Photochem. Rev. 2003, 4, 125-143. [CrossRef]

13. Shi, Y.; Guo, B.; Corr, S.A.; Shi, Q.; Hu, Y.-S.; Heier, K.R.; Chen, L.; Seshadri, R.; Stucky, G.D. Ordered Mesoporous Metallic MoO 2 Materials with Highly Reversible Lithium Storage Capacity. Nano Lett. 2009, 9, 4215-4220. [CrossRef]

14. Światowska-Mrowiecka, J.; de Diesbach, S.; Maurice, V.; Zanna, S.; Klein, L.; Briand, E.; Vickridge, I.; Marcus, P. Li-Ion Intercalation in Thermal Oxide Thin Films of MoO3 as Studied by XPS, RBS, and NRA. J. Phys. Chem. C 2008, 112, 11050-11058. [CrossRef]

15. Wilcoxon, J.P.; Thurston, T.R.; Martin, J.E. Applications of metal and semiconductor nanoclusters as thermal and photo-catalysts. Nanostruct. Mater. 1999, 12, 993-997. [CrossRef]

16. Abrams, B.L.; Wilcoxon, J.P. Nanosize Semiconductors for Photooxidation. Crit. Rev. Solid State Mater. Sci. 2005, 30, 153-182. [CrossRef]

17. Reddy, K.R.; Bhaskar, T.; Chary, K.V.R. Structure and reactivity of molybdenum oxide catalysts supported on $\mathrm{La}_{2} \mathrm{O}_{3}$-stabilized tetragonal $\mathrm{ZrO}_{2}$. Langmuir 2003, 19, 10795-10802. [CrossRef]

18. Martin-Ramos, P.; Fernández-Coppel, I.; Avella, M.; Martín-Gil, J. $\alpha-\mathrm{MoO}_{3}$ Crystals with a Multilayer Stack Structure Obtained by Annealing from a Lamellar MoS2/g-C3N4 Nanohybrid. Nanomaterials 2018, 8, 559. [CrossRef] [PubMed]

19. de Castro, I.A.; Datta, R.S.; Ou, J.Z.; Castellanos-Gomez, A.; Sriram, S.; Daeneke, T.; Kalantar-zadeh, K. Molybdenum OxidesFrom Fundamentals to Functionality. Adv. Mater. 2017, 29, 1701619. [CrossRef] [PubMed]

20. Datta, R.S.; Haque, F.; Mohiuddin, M.; Carey, B.J.; Syed, N.; Zavabeti, A.; Zhang, B.; Khan, H.; Berean, K.J.; Ou, J.Z.; et al. Highly active two dimensional $\alpha$-MoO3-: X for the electrocatalytic hydrogen evolution reaction. J. Mater. Chem. A 2017, 5, 24223-24231. [CrossRef]

21. Najafpour, M.M.; Shirazi Amin, A.; Balaghi, S.E.; Deljoo, B.; Mousazade, Y.; Jafari, T.; Aindow, M.; Suib, S.L. Transformation of La0.65Sr0.35MnO3 in electrochemical water oxidation. Int. J. Hydrogen Energy 2017, 42, 8560-8568. [CrossRef]

22. Voiry, D.; Yamaguchi, H.; Li, J.; Silva, R.; Alves, D.C.B.; Fujita, T.; Chen, M.; Asefa, T.; Shenoy, V.B.; Eda, G.; et al. Enhanced catalytic activity in strained chemically exfoliated $\mathrm{WS}_{2}$ nanosheets for hydrogen evolution. Nat. Mater. 2013, 12, 850-855. [CrossRef]

23. Scaglione, F.; Xue, Y.; Celegato, F.; Rizzi, P.; Battezzati, L. Amorphous molybdenum sulphide @ nanoporous gold as catalyst for hydrogen evolution reaction in acidic environment. J. Mater. Sci. 2018, 53, 12388-12398. [CrossRef]

24. Stamenkovic, V.R.; Mun, B.S.; Arenz, M.; Mayrhofer, K.J.J.; Lucas, C.A.; Wang, G.; Ross, P.N.; Markovic, N.M. Trends in electrocatalysis on extended and nanoscale Pt-bimetallic alloy surfaces. Nat. Mater. 2007, 6, 241-247. [CrossRef] [PubMed]

25. Wu, R.; Zhang, J.; Shi, Y.; Liu, D.; Zhang, B. Metallic $\mathrm{WO}_{2}$-Carbon Mesoporous Nanowires as Highly Efficient Electrocatalysts for Hydrogen Evolution Reaction. J. Am. Chem. Soc. 2015, 137, 6983-6986. [CrossRef]

26. Zong, X.; Xing, Z.; Yu, H.; Bai, Y.; Lu, G.Q.; Wang, L. Photocatalytic hydrogen production in a noble-metal-free system catalyzed by in situ grown molybdenum sulfide catalyst. J. Catal. 2014, 310, 51-56. [CrossRef]

27. Zhang, Y.; Zang, J.; Han, C.; Jia, S.; Tian, P.; Gao, H.; Wang, Y. Molybdenum oxide and molybdenum carbide coated carbon black as an electrocatalyst for hydrogen evolution reaction in acidic media. Int. J. Hydrogen Energy 2017, 42, 26985-26994. [CrossRef]

28. Li, L.; Zhang, T.; Yan, J.; Cai, X.; Liu, S. (Frank) P Doped $\mathrm{MoO}_{3}-\mathrm{x}$ Nanosheets as Efficient and Stable Electrocatalysts for Hydrogen Evolution. Small 2017, 13, 1700441. [CrossRef] [PubMed]

29. Jin, Y.; Wang, H.; Li, J.; Yue, X.; Han, Y.; Shen, P.K.; Cui, Y. Porous MoO 2 Nanosheets as Non-noble Bifunctional Electrocatalysts for Overall Water Splitting. Adv. Mater. 2016, 28, 3785-3790. [CrossRef] [PubMed]

30. Liao, L.; Wang, S.; Xiao, J.; Bian, X.; Zhang, Y.; Scanlon, M.D.; Hu, X.; Tang, Y.; Liu, B.; Girault, H.H. A nanoporous molybdenum carbide nanowire as an electrocatalyst for hydrogen evolution reaction. Energy Environ. Sci. 2014, 7, 387-392. [CrossRef] 
31. Saadi, F.H.; Carim, A.I.; Velazquez, J.M.; Baricuatro, J.H.; McCrory, C.C.L.; Soriaga, M.P.; Lewis, N.S. Operando synthesis of macroporous molybdenum diselenide films for electrocatalysis of the hydrogen-evolution reaction. ACS Catal. 2014, 4, $2866-2873$. [CrossRef]

32. Ma, L.; Ting, L.R.L.; Molinari, V.; Giordano, C.; Yeo, B.S. Efficient hydrogen evolution reaction catalyzed by molybdenum carbide and molybdenum nitride nanocatalysts synthesized via the urea glass route. J. Mater. Chem. A 2015, 3, 8361-8368. [CrossRef]

33. Wang, H.; Tsai, C.; Kong, D.; Chan, K.; Abild-Pedersen, F.; Nørskov, J.K.; Cui, Y. Transition-metal doped edge sites in vertically aligned MoS2 catalysts for enhanced hydrogen evolution. Nano Res. 2015, 8, 566-575. [CrossRef]

34. Jaramillo, T.F.; Jørgensen, K.P.; Bonde, J.; Nielsen, J.H.; Horch, S.; Chorkendorff, I. Identification of Active Edge Sites for Electrochemical $\mathrm{H}<\mathrm{sub}>2</$ sub $>$ Evolution from MoS $<$ sub $>2</$ sub $>$ Nanocatalysts. Science 2007, 317, $100-102$.

35. Paschalidou, E.M.; Scaglione, F.; Gebert, A.; Oswald, S.; Rizzi, P.; Battezzati, L. Partially and fully de-alloyed glassy ribbons based on Au: Application in methanol electro-oxidation studies. J. Alloy. Compd. 2016, 667, 302-309. [CrossRef]

36. Xue, Y.; Scaglione, F.; Rizzi, P.; Battezzati, L.; Denis, P.; Fecht, H.-J. Electrodeposited platinum on de-alloyed nanoporous gold with enhanced electro-catalytic performance. Appl. Surf. Sci. 2019, 476, 412-417. [CrossRef]

37. Badawy, W.A.; Al-Kharafi, F.M. Corrosion and passivation behaviors of molybdenum in aqueous solutions of different $\mathrm{pH}$. Electrochim. Acta 1998, 44, 693-702. [CrossRef]

38. Lützenkirchen-Hecht, D.; Frahm, R. Corrosion of Mo in KOH: Time resolved XAFS investigations. J. Phys. Chem. B 2001, 105, 9988-9993. [CrossRef]

39. De Rosa, L.; Tomachuk, C.R.; Springer, J.; Mitton, D.B.; Saiello, S.; Bellucci, F. The wet corrosion of molybdenum thin film-Part I: Behavior at $25^{\circ} \mathrm{C}$. Mater. Corros. 2004, 55, 602-609. [CrossRef]

40. He, Z.; Huang, Y.; He, F. Preparation of nanoporous molybdenum film by dealloying an immiscible Mo-Zn system for hydrogen evolution reaction. RSC Adv. 2016, 6, 15390-15393. [CrossRef]

41. Łukaszewski, M.; Soszko, M.; Czerwiński, A. Electrochemical Methods of Real Surface Area Determination of Noble Metal Electrodes-An Overview. Int. J. Electrochem. Sci. 2016, 11, 4442-4469. [CrossRef]

42. Qiu, Y.; Wen, Z.; Jiang, C.; Wu, X.; Si, R.; Bao, J.; Zhang, Q.; Gu, L.; Tang, J.; Guo, X. Rational Design of Atomic Layers of Pt Anchored on Mo2C Nanorods for Efficient Hydrogen Evolution over a Wide pH Range. Small 2019, 15, 1900014. [CrossRef] [PubMed]

43. Hovestad, A.; Bressers, P.M.M.C.; Meertens, R.M.; Frijters, C.H.; Voorthuijzen, W.P. Electrochemical etching of molybdenum for shunt removal in thin film solar cells. J. Appl. Electrochem. 2015, 45, 745-753. [CrossRef]

44. Lange, E. M. Pourbaix: Atlas D’Équilibres Électrochimiques à $25^{\circ} \mathrm{C}$. Unter Mitwirkung zahlreicher Fachgelehrter. Mit vielen Figuren und Tabellen. 644 Seiten, $28 \times 22 \mathrm{~cm}$, Ganzleinen. Verlag Gauthier-Villard \& Cie, Paris. Preis: 140 Frs. Ber. Bunsenges. Phys. Chem. 1963, 67, 851-852.

45. Çakir, O. Chemical etching of aluminium. J. Mater. Process. Technol. 2008, 199, 337-340. [CrossRef]

46. Lu, J.; Zhou, W.; Wang, L.; Jia, J.; Ke, Y.; Yang, L.; Zhou, K.; Liu, X.; Tang, Z.; Li, L.; et al. Core-Shell Nanocomposites Based on Gold Nanoparticle@Zinc-Iron-Embedded Porous Carbons Derived from Metal-Organic Frameworks as Efficient Dual Catalysts for Oxygen Reduction and Hydrogen Evolution Reactions. ACS Catal. 2016, 6, 1045-1053. [CrossRef]

47. Lu, T.H.; Chen, C.J.; Basu, M.; Ma, C.G.; Liu, R.S. The CoTe 2 nanostructure: An efficient and robust catalyst for hydrogen evolution. Chem. Commun. 2015, 51, 17012-17015. [CrossRef] [PubMed]

48. Hou, Y.; Wen, Z.; Cui, S.; Ci, S.; Mao, S.; Chen, J. Hybrid Electrocatalysis: An Advanced Nitrogen-Doped Graphene/CobaltEmbedded Porous Carbon Polyhedron Hybrid for Efficient Catalysis of Oxygen Reduction and Water Splitting (Adv. Funct. Mater. 6/2015). Adv. Funct. Mater. 2015, 25, 871. [CrossRef]

49. Ma, F.X.; Wu, H.B.; Xia, B.Y.; Xu, C.Y.; Lou, X.W. Hierarchical $\beta-M o 2 C$ Nanotubes Organized by Ultrathin Nanosheets as a Highly Efficient Electrocatalyst for Hydrogen Production. Angew. Chemie Int. Ed. 2015, 54, 15395-15399. [CrossRef]

50. Schmickler, W.; Bockris, J.O.; Khan, S.U.M. Surface Electrochemistry, a Molecular Level Approach; Plenum Press: New York, NY, USA; London, UK, 1993.

51. Yang, X.; Xu, W.; Cao, S.; Zhu, S.; Liang, Y.; Cui, Z.; Yang, X.; Li, Z.; Wu, S.; Inoue, A.; et al. An amorphous nanoporous PdCuNi-S hybrid electrocatalyst for highly efficient hydrogen production. Appl. Catal. B Environ. 2019, 246, 156-165. [CrossRef]

52. Gong, M.; Zhou, W.; Tsai, M.-C.; Zhou, J.; Guan, M.; Lin, M.-C.; Zhang, B.; Hu, Y.; Wang, D.-Y.; Yang, J.; et al. Nanoscale nickel oxide/nickel heterostructures for active hydrogen evolution electrocatalysis. Nat. Commun. 2014, 5, 4695. [CrossRef] [PubMed]

53. Murthy, A.P.; Theerthagiri, J.; Madhavan, J. Insights on Tafel Constant in the Analysis of Hydrogen Evolution Reaction. J. Phys. Chem. C 2018, 122, 23943-23949. [CrossRef]

54. Tang, Q.; Jiang, D. Mechanism of Hydrogen Evolution Reaction on 1T-MoS2 from First Principles. ACS Catal. 2016, 6, $4953-4961$. [CrossRef]

55. Conway, B.E.; Tilak, B.V. Interfacial processes involving electrocatalytic evolution and oxidation of $\mathrm{H}_{2}$, and the role of chemisorbed H. Electrochim. Acta 2002, 47, 3571-3594. [CrossRef]

56. Xiong, Q.; Zhang, X.; Wang, H.; Liu, G.; Wang, G.; Zhang, H.; Zhao, H. One-step synthesis of cobalt-doped MoS 2 nanosheets as bifunctional electrocatalysts for overall water splitting under both acidic and alkaline conditions. Chem. Commun. 2018, 54, 3859-3862. [CrossRef] [PubMed]

57. Cardoso, J.A.S.B.; Amaral, L.; Metin, Ö.; Cardoso, D.S.P.; Sevim, M.; Sener, T.; Sequeira, C.A.C.; Santos, D.M.F. Reduced graphene oxide assembled Pd-based nanoalloys for hydrogen evolution reaction. Int. J. Hydrogen Energy 2017, 42, 3916-3925. [CrossRef] 
58. Wu, Y.P.; Zhou, W.; Zhao, J.; Dong, W.W.; Lan, Y.Q.; Li, D.S.; Sun, C.; Bu, X. Surfactant-Assisted Phase-Selective Synthesis of New Cobalt MOFs and Their Efficient Electrocatalytic Hydrogen Evolution Reaction. Angew. Chem. Int. Ed. 2017, 56, 13001-13005. [CrossRef] [PubMed]

59. Abbaspour, A.; Norouz-Sarvestani, F. High electrocatalytic effect of Au-Pd alloy nanoparticles electrodeposited on microwave assisted sol-gel-derived carbon ceramic electrode for hydrogen evolution reaction. Int. J. Hydrogen Energy 2013, 38, 1883-1891. [CrossRef]

60. Li, S.; Sirisomboonchai, S.; An, X.; Ma, X.; Li, P.; Ling, L.; Hao, X.; Abudula, A.; Guan, G. Engineering interfacial structures to accelerate hydrogen evolution efficiency of MoS2 over a wide $\mathrm{pH}$ range. Nanoscale 2020, 12, 6810-6820. [CrossRef]

61. Li, X.; Yang, L.; Su, T.; Wang, X.; Sun, C.; Su, Z. Graphene-coated hybrid electrocatalysts derived from bimetallic metal-organic frameworks for efficient hydrogen generation. J. Mater. Chem. A 2017, 5, 5000-5006. [CrossRef]

62. Sun, X.; Huang, H.; Wang, C.; Liu, Y.; Hu, T.L.; Bu, X.H. Effective CoxSy Hydrogen Evolution Reaction Electrocatalysts Fabricated by In Situ Sulfuration of a Metal-Organic Framework. ChemElectroChem 2018, 5, 3570. [CrossRef]

63. Hu, Z.; Huang, J.; Luo, Y.; Liu, M.; Li, X.; Yan, M.; Ye, Z.; Chen, Z.; Feng, Z.; Huang, S. Wrinkled Ni-doped Mo2C coating on carbon fiber paper: An advanced electrocatalyst prepared by molten-salt method for hydrogen evolution reaction. Electrochim. Acta 2019, 319, 293-301. [CrossRef]

64. Barbir, F. Chapter Three-Fuel Cell Electrochemistry. \{PEM\} Fuel Cells, 2nd ed.; Academic Press: Boston, MA, USA, 2013; pp. 33-72, ISBN 978-0-12-387710-9.

65. Chen, L.; Yang, S.; Qian, K.; Wei, W.; Sun, C.; Xie, J. In situ growth of N-doped carbon coated CoNi alloy with graphene decoration for enhanced HER performance. J. Energy Chem. 2019, 29, 129-135. [CrossRef]

66. Li, W.; Wang, X.; Xiong, D.; Liu, L. Efficient and durable electrochemical hydrogen evolution using cocoon-like MoS 2 with preferentially exposed edges. Int. J. Hydrogen Energy 2016, 41, 9344-9354. [CrossRef]

67. Pierozynski, B. Hydrogen evolution reaction at Pd-modified carbon fibre and nickel-coated carbon fibre materials. Int. J. Hydrogen Energy 2013, 38, 7733-7740. [CrossRef]

68. Pierozynski, B.; Mikolajczyk, T.; Turemko, M.; Czerwosz, E.; Kozlowski, M. Hydrogen evolution reaction at Pd-modified carbon fibre in 0.1 M NaOH. Int. J. Hydrogen Energy 2015, 40, 1795-1799. [CrossRef]

69. Sukeri, A.; Bertotti, M. Nanoporous gold surface: An efficient platform for hydrogen evolution reaction at very low overpotential. J. Braz. Chem. Soc. 2018, 29, 226-231. [CrossRef]

70. Wu, M.; Ke, S.; Chen, W.; Zhang, S.; Zhu, M.; Zhang, Y.; Foo, M.L.; Tang, L. Optimization of the facet structure of cobalt oxide catalysts for enhanced hydrogen evolution reaction. Catal. Sci. Technol. 2020, 10, 1040-1047. [CrossRef]

71. Nayak, A.K.; Verma, M.; Sohn, Y.; Deshpande, P.A.; Pradhan, D. Highly active tungsten oxide nanoplate electrocatalysts for the hydrogen evolution reaction in acidic and near neutral electrolytes. ACS Omega 2017, 2, 7039-7047. [CrossRef] [PubMed]

72. Kashfi-Sadabad, R.; Yazdani, S.; Huan, T.D.; Cai, Z.; Pettes, M.T. Role of Oxygen Vacancy Defects in the Electrocatalytic Activity of Substoichiometric Molybdenum Oxide. J. Phys. Chem. C 2018, 122, 18212-18222. [CrossRef] 